\title{
An (un)desirable trade of harms? How elite athletes might react to medically supervised 'doping' and their considerations of side-effects in this situation
}

\author{
Marie Overbye ${ }^{1}$ \\ ${ }^{1}$ Faculty of Health Sciences and Sport, University of Stirling, Pathfoot building, J008, Stirling FK9 4LA, \\ United Kingdom. Phone: (+44) 1786466467 Email address: marie.overbye@stir.ac.uk \\ Corresponding author: Marie Overbye
}

Accepted refereed manuscript of:

Overbye M (2018) An (un)desirable trade of harms? How elite athletes might react to medically supervised 'doping' and their considerations of side-effects in this situation, International Journal of Drug Policy, 55, pp. 14-30.

DOI: 10.1016/j.drugpo.2017.12.019

(C)2018, Elsevier. Licensed under the Creative Commons Attribution-NonCommercial-NoDerivatives 4.0 International http://creativecommons.org/licenses/by-nc-nd/4.0/ 


\section{An (un)desirable trade of harms? How elite athletes might react to medically supervised 'doping' and their considerations of side-effects in this situation}

Background: The zero-tolerance approach to doping in sport has long been criticised. Legalising 'doping' under medical supervision has been proposed as a better way of protecting both athletes' health and fair competition. This paper investigates how elite athletes might react if specific doping substances were permitted under medical supervision and explore athletes' considerations about side-effects in this situation. The results are interpreted using a framework, which views elite sport as an exceptional and risky working environment.

Methods: 775 elite athletes (mean age: $21.73, \mathrm{SD}=5.52$ ) representing forty sports completed a web-based questionnaire (response rate: $51 \%$ ) presenting a scenario of legalised, medically supervised 'doping'.

Results: $58 \%$ of athletes reported an interest in one or more of the 13 proposed substances/methods. Athletes' interest in a specific product was linked to its capacity to enhance performance levels in the athletes' particular sport and depended on gender and age. $23 \%$ showed interest in either one or more of erythropoietin (EPO), anabolic-androgenic steroids (AAS), blood transfusions and/or Growth Hormone if permitted and provided under qualified medical supervision. Male speed and power sports athletes of increasing age had the highest likelihood of being interested in AAS (41\%, age 36), female motor-skill sports athletes had the lowest $(<1 \%$, age 16). 59\% feared side-effects. This fear kept $39 \%$ of all athletes from being interested in specific substances/methods whereas $18 \%$ declared their interest despite fearing the side-effects.

Conclusion: Interpreting results with the understanding of sport as an exceptional and risky working environment suggests that legalising certain 'doping' substances under medical supervision would create other/new types of harms, and this 'trade-off of harms and benefits' would be undesirable considering the occupational health, working conditions and well-being of most athletes. Assessing the risks and harms produced/reduced by specific drugs when considering sport as a precarious occupation may prove useful in composing the Prohibited List and reducing drug-related harm in sport.

Keywords: Anti-doping policy, drug control model, the prohibited list, harm reduction, health, sport. 


\section{Introduction}

This paper aims to contribute to discussions about the regulation of drugs in sport by empirically investigating how elite athletes might react if 'doping' was permitted under medical supervision and explore athletes' considerations of side-effects in this situation. The implications of results, i.e., the tradeoff between harms and benefits ${ }^{1}$ of such approach for athletes, are interpreted using a conceptual framework that views sport as an exceptional and risky working environment.

Today 'doping' is prohibited in sport mainly to secure a level playing field, to protect athletes' health, to preserve the integrity of sport and to set a good example. Since the establishment of the World Antidoping Agency (WADA) in 1999 and particularly the implementation of the first World Anti-doping Code in 2004, anti-doping rules and efforts have undergone a process of intensification, standardisation and harmonisation. Today's anti-doping programme is comprehensive (WADA, 2015) and, if caught, doping athletes risk four years' ineligibility for a first-time doping violation.

The current fight against doping faces multiple challenges, and the legitimacy of anti-doping efforts are greatly contested. For example, criticism has targeted a lack of clarity in the rationale justifying the aims of anti-doping policy (e.g. Hanstad \& Waddington, 2009; Mazanov \& Connor, 2010; Møller \& Dimeo, 2014; Waddington \& Smith, 2009), or the justifiability of doping bans (e.g. Savulescu et al., 2004; Tamburinni, 2007). It has been argued that the fight against doping is expressing a 'moral panic' executed as moral regulation (Critcher, 2014) or constituting a fear-based policy mirroring drugs myths from the non-sporting world, resulting in measures anchored in fear, morality and prejudice rather than in evidencebased and reasoned arguments (Coomber, 2014) without any clear evidence-based knowledge of drugs side-effects (Kayser \& Broers, 2015; Kayser \& Smith, 2008).

Others have argued that a zero-tolerance policy may have a negative impact on doping athletes' health because it alters supply chains, pushing consumers from "culturally embedded dealers" towards the "black market" (Fincoeur, Van de Ven \& Mulrooney, 2015). Furthermore, the current punitive approach has been denounced as ineffective in preventing athletes from doping (Kayser et al., 2007; Waddington \& Smith, 2009), a notion supported by empirical studies illustrating that athletes with doping experiences do not regard deterrence elements as credible (Engelberg et al., 2015; Kirby et al., 2011; Pappa \& Kennedy, 2012) and that testing programmes are not regarded by many athletes as a great deterrent (Overbye, 2017). 
Further challenges facing anti-doping efforts are: firstly, the considerable differences in stakeholders' interpretations and implementations of the Wada Code and International Standards worldwide (Dikic et al., 2011; Wagner \& Hanstad 2011; Hanstad \& Loland, 2005; Houlihan, 2014; Siekmann \& Soek, 2010); secondly, flaws at all levels of the system, decreasing its effectiveness (WADA, 2013); thirdly, the very low detection rate (de Hon et al., 2015); and, fourthly, false negative (Ashenden et al., 2011; Lundby et al., 2012) as well as false positive testing results (Delanghe, Bollen, \& Beullens, 2008; Lundby et al., 2008).

Furthermore, the paradoxes and unintended effects of anti-doping measures have attracted more attention in recent years. The paradoxes relate to how the comprehensive set of rules developed to protect athletes' health and secure equality and fairness in sport have created new forms of inequalities between athletes subjected to different anti-doping regimes (Efverström et al., 2016; Hanstad, Skille \& Loland, 2010; Waddington, 2010; Overbye \& Wagner, 2014; Overbye, 2016) and situations which may have negative effects on some athletes' health (Bourdon, Schoch, Broers \& Kayser, 2015; Overbye \& Wagner, 2013; Lentillon-Kaestner, 2013). Other issues of concern relate to: the collateral damage of excessive rule enforcement, e.g. the high proportion of athletes punished due to unintentional anti-doping rule violations (Cox, 2014; de Hon \& Bottenburg, 2016; McArdle, 2015; Moston \& Engelberg, 2016; Pluim, 2008), the unintended effects of the implementation of certain anti-doping rules, such as athletes' negative experiences and emotions associated with their obligation to report their whereabouts (Bourdon et al., 2015; Hanstad \& Loland 2009, Overbye \& Wagner, 2014; Valkenborg et al., 2014); challenges in the administration of Therapeutic Use Exemptions (Bourdon et al., 2015; Overbye \& Wagner, 2013); unease during urine doping testing (Bourdon et al., 2015; Elbe \& Overbye, 2014; Overbye, 2013, 2016); and, finally, athletes' increasing worries about and avoidance of medicines for fear that they might be on the Prohibited List (NN).

\section{A critical appraisal of the zero-tolerance approach and the aims of this study}

In this context it is relevant to critically assess the benefits and costs of the system, for example with regard to not only its success in reducing doping (de Hon, 2016) but also its ability to reduce (and not cause) harm to athletes. Researchers have argued that the current anti-doping regime has gone too far in fighting doping in sport (e.g. Møller, 2010, 2011; Kayser, Mauron, \& Miah, 2007), suggesting that anti- 
doping produces problems of greater impact than those which are solved (Møller \& Dimeo, 2014; Kayser et al., 2007; Kayser \& Broers, 2015). Hence, it has been argued that current anti-doping efforts have too many negative effects, are too extensive, yet too ineffective, and very costly (e.g. Kayser et al., 2007); from a public health perspective the cost of anti-doping is difficult to justify (Kayser et al., 2007; Kayser \& Broers, 2012); and a relaxation of rules along with harm reduction measures may come at lower cost and/or with fewer consequences for society and the individual compared with the current zero-tolerance, abstinence-based approach (Kayser \& Broers, 2012; 2015; Kayser \& Tollener, 2017).

Consequently, several researchers have argued that the current 'zero tolerance' approach to 'doping' is inappropriate and that implementing strategies based on harm minimisation would be better alternatives. A variety of alternative models for new drug-control policies in sport has been proposed aimed at protecting health as a replacement for the current punitive doping control measures (e.g. Kayser \& Smith, 2008; Kayser \& Broers, 2015; Kayser \& Tollener, 2017; Kirkwood, 2009; Lippi et al., 2008; Steward \& Smith, 2015; Savulescu, 2015). Examples of such strategies are a relaxation of anti-doping rules within the boundaries of acceptable health risks, accompanied by harm-reduction measures (Kayser \& Tollener, 2017); and allowing 'doping' under medical supervision (e.g. Kayser, Mauron \& Miah, 2005, 2007; Kirkwood, 2009; Savulescu, Foddy, Clayton, 2004; Smith \& Steward, 2008). Some proposals also seem to be based on assumptions that 'doping' is widely used in elite sport and that (most) athletes will use 'doping' regardless of either its impact on health or the illegal status of the drug. Furthermore, a key rationale behind suggesting legalisation or partial legalisation of drugs under medical supervision is the notion that the level of playing field is a myth and that the focus ought to be on minimising health harms rather than on punishment. In this way, it is expected that permitting drugs (or drugs to a certain limit) under medical supervision may provide athletes with a 'healthier' alternative because, firstly, athletes and doctors would not need to hide their involvement in using certain substances or methods and, secondly, the possible side-effects of different methods could be dealt with more effectively (e.g. Kayser et al., 2005). Besides this, it has been argued that legalisation would increase fairness because all athletes would be given the same opportunity of using performance-enhancing drugs (Savulescu et al., 2004; Savluescu, 2015; Tamborinni, 2007). 
Yet the proposals for legalising 'doping' or certain drugs such as anabolic-androgenic steroids (AAS) and erythropoietin (EPO) under medical supervision in sports are controversial and run counter to the intensification of anti-doping efforts recent years. However, although introducing different harm reduction approaches to drug use in society has become increasingly common (Cook, Bridge \& Stimson, 2010), and shown to be useful in protecting the health of drug users in different settings, including among gym users (Kimergaard \& McVeigh, 2014), we do not know if a radical change in the current strategy would actually reduce health risks in the social field of elite sport, or, how permitting 'doping' under medical supervision in sport would be received by athletes.

To date, one drawback to any discussion on legalising 'doping' under medical care (and similar strategies) in an elite sport context is the lack of empirical studies informing discussions. In particular, researchers seldom consider ways in which the cultural and economic environment of sport may have an impact on legalised, medical supervised 'doping'. Moreover, although it has been stressed that legalisation of doping might induce more athletes to use currently illegal drugs (Savulescu et al., 2004; Kayser \& Smith, 2008); there is still a lack of discussion and reflection on what impact medically supervised 'doping' (and similar strategies) might have on athletes in general and on whether athletes would be in favour of such change. Exceptions to this are the studies of Holm (2007) and Haugen (2011), both of whom apply a game theoretical approach, arguing, for instance, that legalising doping could create other problems and would not make doping a safer practice. Additionally Fry (2017) argues that the high levels of athletes support for anti-doping policy as well as the atypical harms from sports doping must be considered.

Empirical studies suggest that athletes support certain limits as well as a control system but sometimes vary in their opinions on what it should be permitted to use (Christiansen \& Møller, 2007; LentillonKaestner, 2015a; Overbye, 2013). When asked directly, few athletes favour legalisation of doping (Valkenburg et al., 2014; Fürhapter el al., 2015; Stamm et al., 2008) or report that they would start using a currently banned substance if it was removed from the list (Alaranta et al., 2006). Several studies have evaluated athletes' reflections on 'doping' when its use is prohibited in sport, measuring their views on the influence of side-effects, the risk of being caught and/or medical supervision (Backhouse, Whitaker, \& Petróczi, 2013; Bloodworth \& McNamee, 2010; Bloodworth et al., 2012; Connor, Wulff, \&, Mazanov, 
2013; Dimeo et al., 2013; Gucciardi, Jallah \& Donovan, 2011; Overbye et al., 2013; Strelan \& Boeckmann, 2006; Wulff, Mazanov \& Connor, 2016). Importantly, in these studies 'doping' was considered an illegal practice and the name and particular characteristic of the particular substance was seldom disclosed to the athletes (possibly making it more difficult for them to assess). Since the issue of legality was still an issue, athletes' reactions may (also) be understood as a measure of morality rather than a measure of their actual interest in using a certain drug if permitted, their willingness to run a severe health risk or their belief whether health risks would actually materialise. Hence, results from these studies cannot be understood as a measure of how athletes might react if 'doping' was legalised under medical supervision.

Elite athletes' opinions on and possible reactions to legalising 'doping' (or specific drugs like AAS and EPO) under medical supervision are important, especially considering that elite athletes are i) those who would be most affected, and ii) the main stakeholders when considering the legitimacy of anti-doping rules (Efverström et al., 2016; Overbye, 2016). Moreover, as pointed out by Møller (2010), one argument that both supporters and opponents of doping legalisation seem to agree on is that the interests of athletes should carry considerable weight. In spite of these considerations, no studies have so far investigated how a larger group of elite athletes might react to medically supervised 'doping', if permitted, or explored athletes' thoughts about the side-effects of 'doping', if supervised by medical practitioners.

Consequently, based on a questionnaire survey of 775 Danish elite athletes, the first part of this study investigates: i) how elite athletes may react to legalised, medically supervised 'doping' provided it took place under qualified medical guidance; ii) whether athletes would consider the side-effects in this situation; iii) if so, what side-effects they fear and what influence this fear has on their thoughts about trying the substances; and iv) whether athletes of different gender, age and type of sport differ in their responses. The second step is to consider what impact the introduction of medically supervised 'doping' may have on elite athletes in general - and whether this strategy would be a desirable trade-off between harm and benefit. The discussion of results is based on a conceptual framework which views elite sport as an exceptional and risky working environment. The final section concludes that anti-doping (as a drugregulation model in sport) may benefit to a higher degree from a risk-based assessment considering the particular working environment of athletes when deciding what should be permitted or prohibited in sport. 
It is, however, beyond the scope of this paper to outline the solution that could solve the current challenges. As noted by Kayser and Broers (2013), if an easy option existed, this would (most likely) already have been suggested and applied. Rather, the paper explores and introduces another view of drug regulation based on the notion of sport as an exceptional and often extreme working environment in which many actors interact and profit. Thus, the paper contributes to discussions of how 'harms' could be reduced in an elite sport setting. Furthermore, by presenting the challenges, possible reactions, deliberations and reservations from the athletes' perspective, the study contributes empirical knowledge to an area which so far has been inadequately represented in current discussions about drug regulation in sport.

Before presenting the methodological design and the results the theoretical inspiration and framework guiding the discussion and conclusions in this paper will be outlined briefly.

\section{Understanding elite sport as an exceptional and risky working environment}

This paper draws on Rhodes' (2009) framework, which envisages a risk environment as comprising types of environment (physical, social, economic, policy) interacting with levels of environmental influence (micro, macro), to outline a conceptual framework that considers these elements in sport working environments.

Elite sport constitutes a unique social practice comprising an exceptional and risky working environment. ${ }^{2}$ Drug use, as well as drug-related harm to health in sport, is shaped by and contingent upon the particular social context in which various actors interact and are mutually interdependent.

Today, elite sport can be perceived as a social practice intertwined with the market, politics and medicine. The changing patterns of, and observable increase in, drug use in sport have been explained using concepts by Norbert Elias (1978) as two, largely autonomous sets of social processes in society (e.g. the medicalisation of life) and in sport (e.g. its professionalisation, politicisation, commercialisation), leading to an increased focus on results and competition (Waddington, 1996, 2000; Waddington \& Smith, 2009). Figurational sociology has been applied to understand issues related to the doctor-athlete relationship and drug use in sport (e.g. Malcolm, 2009; Malcolm \& Sheard, 2002; Waddington, 1996) and 
how and/or why current anti-doping policy has numerous unintended consequences when implemented (Hanstad, 2009; Overbye, 2013, 2016; Waddington, 2010; Wagner, 2010).

Although this paper does not have an explicit figurational framework, it is inspired by this approach, which provides a foundation for an understanding of the complexity of mutual interdependencies and the unpredictability of outcomes with regard to the regulation of drugs in sport examined in this paper.

The elite sport figuration constitutes a matrix of mutually interdependent networks between individual and organisational actors (players), creating multiple layers of the game ${ }^{3}-$ a game which is played at regional, national, international and global levels. The synergistic relationships between key stakeholders have implications for other institutional and interpersonal relationships associated with sport (Anderson \& Jackson, 2013). A figurational framework enables an understanding of the complexity of factors that may influence social practices in elite sport as well as the dynamic and changing character of these social practices. When the number of interdependent actors increases, social interaction becomes complex - and as a result uncontrollable - thus creating unpredictable games that are likely to lead to unintended consequences (Elias, 1978). These independencies may create both tensions and temporary equilibrium providing opportunities as well as imposing constraints for human beings in their social dealings.

This framework/understanding has at least two interrelated implications. Firstly, athletes' use of various drugs must be considered in its social and cultural context, comprising interactions and interdependencies between individuals and environments. Secondly, a variety of different actors (including social, sporting and political institutions) potentially play an important role in harm production or reduction with regard to drug use in sport.

In addition, Rhodes $(2002,2009)$ emphasises that one way of defining a risk environment is to see it as the space - whether social or physical - in which a variety of factors interact to increase the chances of harm occurring. Consequently, the following section provides an insight into some unique features in the particular working environment of elite sport (i.e. embedded in the sport figuration) which increase the risk of harm to athletes - and also help to explain why elite sport is replete with endogenous as well as exogenous risks which foster risk environments and occupational risks. ${ }^{4}$ 


\section{Elite sport an occupation with endogenous and exogenous risks}

The dominant logic in elite sport is a competition logic governed by a win-lose code (Tangen, 2004) although other codes, for example enhancement/decline, clean/doped and healthy/unhealthy, may play a role as well (Wagner, 2009). Athletes are expected to be influenced by competition logic and always to strive for performance enhancement and victory (illustrated by the Olympic motto "citius, altius, fortius"). Embedded in the environment is a normalised 'culture of risk' (Bette, 2004; Safai, 2003; Nixon, 1992) in which pain and 'playing hurt' are normalised (Mayer \& Thiel, 2016; Roderick, 2006a) - norms which may be internalised and encouraged by, for example, coaches, managers and doctors (Anderson \& Jackson, 2013; Safai, 2003; Roderick, 2006a; Waddington, 2015).

The commercialisation and professionalisation of sport provide benefits for many different actors in the sport figuration. Simultaneously, commercial pressures place demands on various organisations and individuals to perform well continually (Anderson \& Jackson, 2013). The organisation of work, employment models and working conditions may also have an impact on legal or illegal drug use and athletes' perceptions of performance-enhancing drugs (Aubel \& Ohl, 2014; Ohl et al., 2015; Smith, 2017). Athletes (as a labour force) are central to the success of sports organisations and teams, and sporting results are important for coaches' and managers' careers and financial opportunities (Andersen \& Jackson, 2013; Roderick, 2006a,b). Similarly, income and employment models, support from sports organisations or national funding bodies as well as sponsorship deals are often closely linked to the athlete's or the team's ability to continuously perform at a high level and deliver good results.

Thus, athletes face significant occupational pressures to perform well or else risk replacement (Roderick, 2006b). Consequently, it seems likely that most elite athletes to some degree internalise the competition logic and the core norms of the sport ethic. At the same time, the many actors involved in the elite sports figuration, the interdependencies and intertwining logics with other fields (such as the market, medicine and politics) together create a unique and risky working environment which differs significantly from that of other social fields.

\section{The pivotal role of the body and the interdependence with sports medicine}

The athletes' body plays an indispensable role in sport (Bette, 2004). The often relatively short-lived, 
fragile and uncertain nature of athletes' careers may add to the pressures on athletes (Roderick, 2006a,b). Several risks facing elite athletes can be directly associated with threats to the body's functionality: the risks of injury, illness, declining performance and ageing (Bette, 2004; Roderick, 2006b). From this perspective, drug use may be seen as a coping strategy or predictable reaction to the inherent risks of sport (Bette, 2004; cf. previous section).

In line with this, the significant role of doctors and the centrality of the doctor-athlete relationship with regard to drug use have been emphasised (Brissonneau, 2010; Hoberman, 2002; Waddington, 1996, 2015; Waddington \& Smith, 2009). Sports physicians have played a key role in pioneering the development and use of performance-enhancing drugs (Hoberman, 2002; Waddington, 1996). For example, extreme working conditions faced by cyclists in the 1970s led to closer cooperation with physicians and medical staff, whose reasons for providing drugs ranged from relieving the pain suffered by their 'friends' (the riders) to perceiving AAS as a logical treatment to ensure a 'healthy' working force (Brissonneau, 2010).

The competing obligations and dilemmas facing doctors when providing drugs can also be seen, firstly, in the cultural and economic context (cf. previous sections), in which relationships between key stakeholders produce expectations and pressures on doctors that may compromise professional standards and/or the provision of healthcare (Anderson \& Jackson, 2013); and, secondly, in the blurred lines and contradictory role of sports medicine, particularly the dual role of doctors in restoring athletes' health while simultaneously preparing athletes for top performance (Tscholl, Feddermann, Junge, \& Dvorak, 2009; McNamee \& Phillips, 2011). These challenges faced by doctors must also be considered from the perspective of the high demands placed on elite athletes' bodies, which sometimes increase athletes' needs for certain medicines. While injuries and some chronic illnesses (e.g. exercise-induced asthma) are an inevitable part of elite sport working life, the required treatments are often defined as doping. Cases of this sometimes blurred boundary between legal therapeutic treatment and the illegal use of medical substances occasionally occur when Therapeutic Use Exemptions (TUEs) are granted in elite sport (Overbye \& Wagner, 2013). 


\section{Methods}

\section{Procedure and participants}

A total of 775 Danish athletes replied to a web-based questionnaire (response rate: $51 \%$ ); of these $60 \%$ were male and $40 \%$ female athletes with an average age of 21.73 years. Forty sports were represented and grouped (drawing on Alaranta et al., 2006) according to the main physical demands of the sport. The overall distribution of athletes is set out in Table 1. Among the athletes supported by Team Danmark, 14\% were categorised (by Team Danmark) as "world-class athletes" (i.e. ranked eight or better at the most recent world championship or Olympic Games); 26\% were defined as "elite athletes" (national senior team athletes with a high level of performance); and 61\% were "Team Danmark athletes" (mostly upcoming talented athletes in national teams for junior or senior). A majority of athletes regarded AAS, Growth hormone (GH), EPO and blood transfusions to have an effect in their sport. A contextualisation of athletes' practices and preferences in relation to legal performance enhancing products, doping proximity, competition logic and norms in the training environment is set out in Table A1.

\section{$>$ Insert table $1<<$}

\section{Measures}

The findings presented in this paper were part of a survey assessing elite sport life and elite athletes' views on and experience with legal performance-enhancing drugs and methods (Overbye, 2013). The questions were inspired by the scenario of medically supervised doping and by findings from 32 interviews with current and former elite athletes about their attitudes towards drugs and side-effects.

\section{Q1: Legal, medically supervised 'doping' scenario}

Athletes were invited to imagine the following situation:

i) that the substances listed below were made legal;

ii) that you could have the drugs provided; and

iii) that you were ensured qualified medical supervision. 
Subsequently, a list of substances/methods was presented and the athletes were asked which substances they would be interested in trying. Some of the listed substances/methods were only illegal if a certain threshold level were exceeded or if certain brands were used. ${ }^{5}$ It was then noted that some substances/methods were currently prohibited whereas other were legal - and (again) it was emphasised that the athletes should answer as if all the listed substances and methods were legal. It was stressed that affirmative answers would not be interpreted as an indication that the athlete was currently using a particular substance, nor that the athlete was planning to do so in future. The degree of interest in trying a specific substance/method was reported by answering either: 'yes', 'most likely yes', 'most likely not', 'no', 'no, because I do not think it has an effect in my sport' and 'I really do not know'. In addition, an open-ended answer possibility was provided at the end of the question, enabling athletes to comment on the question or elaborate on their answers. The category "no, because I do not think it has an effect in my sport' was introduced to discriminate between athletes who do not wish to use a specific drug and athletes who did not answer affirmatively because they did not think the drug would make a difference to their performance levels in their sport.

Giving an affirmative answer to a question involving medically supervised 'doping' - even when one is told 'doping' is legal - must be regarded as particularly sensitive. Athletes' use of doping is condemned (perhaps particularly in Denmark, where anti-doping measures also involve drug testing in some gyms as well as among recreational athletes); therefore, athletes might feel they are taking a great risk by reporting an interest in trying out say AAS or EPO. Consequently athletes were asked only if they were interested in trying a certain substance/method. Thus, the athletes report whether they would like to use a particular substance if this was legal; by answering affirmatively they do not commit themselves to systematically use the substance in higher doses over a longer period of time.

\section{Q2: Athletes' reflections on side-effects}

A follow-up question asked whether athletes had considered any side-effects of the substances when they answered the first question (Q1). Athletes who reported they feared side-effects were subsequently asked how this fear influenced their answers in two follow-up questions. Firstly, if this worry made them refrain from wanting to try one or more substances - here, athletes were asked to elaborate on what type of side- 
effects they worried about in an open-ended answer category. Secondly, if the athletes - despite their fear of side-effects - were interested in trying one or more of the listed substances/methods.

\section{Data analysis}

The data were analysed using SPSS 22. Bivariate distributions were used to examine the athletes' degree of interest in different substances if these were legal and provided with qualified medical supervision as well as their considerations of side-effects in this situation and how (or whether) these depended on gender, age and type of sport. Differences were assessed using chi-square $\left(\mathrm{x}^{2}\right)$ tests and gamma tests (twotailed). Values of less than 0.05 were considered statistically significant. Logistic regression was used to identify whether age, gender and sport type were significant predictors of interest in EPO and AAS. Dependent variables were recoded into binary variables (yes/most likely yes $v s$. no/ most likely no). Using logistic regression analyses (backwards manual stepwise elimination), two separate models were tested, one for EPO and one for AAS. Variables included in the logistic regression model were: i) gender, age [interval scale level] and type of sport [team sports/speed and power/endurance/motor-skill sports]. Both models included any two-factor interaction terms. "I don't know/"No, because I do not think it has an effect in my sport" answers were excluded from the statistical analysis. Odds ratios (OR) and 95\% confidence intervals are reported.

\section{Results}

How many elite athletes would be interested in trying different substances if legal and provided under qualified medical supervision?

Results showed that many athletes would not be interested in trying different substances/methods even when legal and provided under qualified medical supervision (Figure 1). Vitamin and mineral injections were the most popular substance/methods (39\%) and diuretics the least popular (10\%). More than half $(58 \% ; n=450)$ the athletes would be interested in trying one or more of the 13 substances/methods [25\% indicated an interest in $1-2$ substances; $23 \%$ in $3-6$ substances and $10 \%$ were interested in 7-13 substances]. Reasons for not answering affirmatively (42\%) were because the athlete: i) 
was not interested in trying the substance/method; ii) did not believe the substance/method would enhance performance levels in his/her particular sport [12\% answered this in the case of $1-2$ substances; $6 \%$ in the case of 3-6 substances and $4 \%$ in the case of 7-13 substances]; or iii) the athletes were unsure what to answer $[17 \%$ were unsure what to answer in the case of $1-2$ items; $7 \%$ in the case of $3-6$ items and $5 \%$ in the case of 7-13 items].

Almost one quarter $(23 \%)$ of the athletes showed interest in trying at least one of the four assumable most effective performance-enhancing substances/ methods: EPO, AAS, blood transfusions and GH, if these were made legal and provided with qualified medical supervision. A minority (3\%) would be interested in all four substances/methods: EPO, AAS, blood transfusions and GH; $4 \%$ in three out of the four; $8 \%$ in two of the four; and $9 \%$ would be interested in only one of the four substances/methods.

\section{$>>$ Figure $1<<$}

\section{Would athletes of different gender, age and type of sport react differently to legalised, medical supervised 'doping'?}

On a binary scale (yes/most likely yes $v s$. no/most likely not) using bivariate distributions, differences between groups of athletes were found in all items except one (diet medicines). Male athletes indicated interest more frequently than female athletes in trying: AAS (20\% vs. $3 \%$; $<<0.001)$; blood transfusions ( $21 \%$ vs. $8 \%$ p $<0.001)$; growth hormone $(24 \%$ vs. $6 \%$; $<0.001)$; EPO or similar means $(23 \%$ vs. $6 \%$; $\mathrm{p}<0.001)$; cortisone $(22 \%$ vs. $4 \%$; $<<0.001)$; stimulating substances $(27 \%$ vs. $9 \%$; $p<0.001)$; cognitive enhancing means $(36 \%$ vs. $25 \%$; $<0.03)$; and drops with sugar and salt as restitution between competitions ( $44 \%$ vs. $25 \%$; $<<0.001)$. On the other hand, female athletes more frequently answered they would be interested in trying medicines that could reduce nervousness ( $31 \%$ vs. $23 \% ; \mathrm{p}=0.024)$. Athletes 20 years and older more frequently reported an interest in trying various substances/methods compared with athletes younger than 20 years of age: AAS ( $9 \%$ vs. $16 \%$; $=0.005)$; blood transfusions $(13 \%$ vs. $19 \%$; $=0.043)$; growth hormone $(24 \%$ vs. $6 \%$; $<<0.00)$; EPO or similar means $(13 \%$ vs. $20 \% ; p<0.00)$; cortisone ( $10 \%$ vs. $20 \%$; $<<0.002)$; stimulating substances ( $14 \%$ vs. $24 \%$; $<<0.005)$; injection of vitamin or mineral supplements $(32 \%$ vs. $47 \%$; $<<0.001)$ and drops with sugar and salt as restitution between competitions ( $32 \%$ vs. $41 \%$; $p=0.024)$. 
Differences between sport types were found (in the following TS $=$ team sports; SP $=$ speed and power sports; $\mathrm{MS}=$ motor-skill sports; $\mathrm{ES}=$ endurance sports): endurance athletes more frequently reported an interest in blood transfusions (32\% vs. TS: 13\%/ SP: 12\%/ MS: 9\%; $<<0.001)$; EPO or similar means (32\% vs. TS: 15\%/ SP: 15\%/ MS: 4\%); respiratory dilators (53\% vs. TS: 30\%/ SP: 30\%/ MS:19\%; $\mathrm{p}<0.001)$. Endurance and speed and power athletes more frequently reported an interest in trying stimulating substances (ES: 29\%/ SP: 25\% vs. TS: 16\%/ MS: 12\%; $\mathrm{p}=0.013$ ) as well as drops with sugar and salt as restitution between competitions (ES: 49\%/ SP: 44\% vs. TS: 31\%;/MS: 24\%; p $<0.001$ ) compared with team sport and motor-skill athletes. Speed and power athletes more frequently reported an interest in trying AAS (SP: 19\% vs. TS: 12\%/ ES: 12\%/ MS: 5\%; p=0.046) and diuretics (SP: $18 \%$ vs. TS: 8\%/ ES: 13\%/ MS: 9\%; $\mathrm{p}=0.017)$. Moreover, speed and power and motor-skill athletes were more likely to be interested in cognitive enhancing means (SP: 40\%/ MS: 42\% vs. TS: $25 \%$ / ES: $30 \%$; $p=0.004$ ). On the other hand, athletes from motor-skill sports more frequently reported an interest in trying medicine to reduce nervousness (MS: 50\% vs. TS: 22\%/ SP: 28\%/ ES: 18\%; p<0.001).

\section{How do athletes vary in their interest in AAS and EPO if legal and provided under medical supervision?}

\section{Anabolic-androgenic steroids}

Logistic regression analyses were conducted to predict the odds that athletes would be interested in trying AAS if legal and provided under medical supervision. The final model (cf. data analysis) was significant $(\chi 2=61.37, \mathrm{df}=5, p<0.000$; Cox and Snell $\mathrm{R} 2=0.096$; Nagelkerke $\mathrm{R} 2=0.177)$ and showed that type of sport, age and gender were significant predictors. The older the athlete, the higher the odds were that they were interested in AAS (OR $1.05(95 \% \mathrm{CI}=1.01-1.09) ; p=0.027)$. Male athletes had higher odds than female athletes for being interested in AAS (OR $9.68(95 \% \mathrm{CI}=4.13,22.71) ; p=0.00)$. Athletes from speed and power sports (OR $4.65 \quad(95 \% \mathrm{CI}=1.31,16.48) ; \quad p=0.017)$, team sports $(\mathrm{OR} 3.03$ $(95 \% \mathrm{CI}=0.87,10.58) ; p=0.083)$ and endurance sport athletes (OR $2.66(95 \% \mathrm{CI}=0.70,10.01) ; p=0.151)$ had higher likelihood than motor-skill sport athletes of being interested in AAS, if permitted. Therefore, the probability that an athlete would be interested in trying AAS if legal and provided with medical guidance 
was greatest among older male athletes from speed and power sports (e.g. 41\%, 36 years old) and lowest among (younger) female athletes from motor-skill sports (e.g. $<1 \%, 16$ years old) (Figure 2).

\section{$>>$ Figure $2<<$}

EPO or similar substances, e.g. CERA, NESP

Logistic regression analyses were conducted to predict the odds that athletes would be interested in trying EPO or similar substances such as CERA, NESP if legal and provided under medical supervision. The final model was significant $(\chi 2=54.73, \mathrm{df}=5, \mathrm{p}<0.00$; Cox and Snell $\mathrm{R} 2=0.092$; Nagelkerke $\mathrm{R} 2=0.16)$ and showed that type of sport, age and gender were significant predictors. The older the athletes, the higher the odds were that they were interested in EPO (OR 1.05 (95\% CI=1.01,1.09); $p=0.021)$. Male athletes had higher odds than female athletes of being interested in EPO (OR $3.58(95 \% \mathrm{CI}=2.03,6.33) ; p=0.00)$. Athletes from endurance sports (OR $14.48(95 \% \mathrm{CI}=3.26,64.43) ; p<0.000)$, team sports (OR 5.56 $(95 \% \mathrm{CI}=1.27,24.29) ; p=0.023)$ and speed and power sports (OR $4.97(95 \% \mathrm{CI}=1.10,22.47) ; p=0.037)$ had a higher likelihood than athletes from motor-skill sports of being interested in EPO. Therefore, the probability that athletes would consider using EPO was greatest for male endurance athletes (e.g. 36 year old, 57\%) - and increased with age - and lowest among younger female athletes from motor-skill sports (16 years old, 1\%) (see Figure 3).

$>$ Figure $3<<$

Do athletes consider side-effects when drugs are provided under medical supervision? If so, how does a fear of side-effects influence athletes' reflections on using drugs?

A majority of athletes (67\%) stated they considered side-effects of the drug/method when reflecting upon which drugs/methods they would use. In the group of athletes who considered side-effects, $88 \%$ reported that they worried about side-effects while $12 \%$ did indeed consider the side-effects but were not afraid of these (see Figure 4). Of the athletes who were afraid of side-effects, $77 \%$ reported that this fear kept them from wanting to try one or more of the substances/methods listed and 35\% reported that, despite their fear 
of side-effects, they would like to try one or more of the listed substances if these were legal and provided under qualified medical assistance.

\section{$>$ Figure $4<<$}

A total of 154 athletes commented on the side-effects they feared when answering the first question (Q1). In addition, eight of the 17 athletes who elaborated on their answers in the open-ended answer option in Q1 also raised concerns about side-effects. Athletes named i) particular side-effects they feared, ii) specific substances/methods they feared; iii) their reservations when answering the question; or iv) had other explanations or comments (See Table A2 in the Appendix for an overview). Below are some indicative responses:

Fear of hormones: "If we assume that all are legal, I would not dare to use hormones and drugs which change the body or can have a damaging impact on body organs, etc." (female athlete, endurance sport)

Drugs if needed: "I would only use some of the listed substances if I had trouble with, for example, injuries or with my diet" (female athlete, team sport)

Unwilling to run health risks: "I would demand documentation saying that there are - or there would be - no side-effects. My sport is not more important than my health" (male athlete, motorskill sport)

Competition logic and accepting risks: "Yes and no, because if everything was legal, then everyone would also take the listed substances. And then, although it was dangerous, it would just be something everyone did to play sport at a high level of performance" (male athlete, team sport)

Fear of permanent damage: "Several of the substances/methods can result in permanent damage, including brain damage, like Ritaline (which could be relevant in my sport), so I would check out the long-term side-effects beforehand" (female athlete, motor-skill sport).

Lack of trust in doctors: "Lack of knowledge and disagreement among medical doctors, so I do not dare trust them" (male athlete; team sport)

Great trust in doctors: "I thought that some of the substances might have deadly side-effects; however, the correct supervision made me surer that I would use some of the substances" (male athlete, team sport) 


\section{Discussion}

The first set of questions set out to explore how elite athletes may react if 'doping' was legal and provided under qualified medical supervision. A key finding was that approximately three quarters of the athletes were not interested in trying AAS, EPO, GH and/or blood transfusions, even if permitted in sport and provided under qualified medical guidance. Additionally, although the results reveal great variations within the athlete group, more than half of the athletes (cf. Figure 1) would not be interested in trying some of the less effective performance-enhancing substances, including products with little or no (or even a possibly positive) impact on health. The great variations within the athlete group are to be expected when one considers the differences in their approach to legal performance-enhancing drugs: these are, firstly, the differences in the patterns of their sport-related use of legal products, for example caffeine, creatine and NSAIDs (Table A1; Overbye, 2013:123); secondly, differences in their practices related to (de)selecting legal products, e.g. whether they had ever refrained from or minimised their use or felt it was important to enhance performance with all available legal products (cf. Table A1); and, thirdly, the differences in how the athletes said they would react if (when) competitors started using a new legal performance-enhancing drug e.g. if they would use the same drug or they would (prefer to) continue to do what they normally did (Table A1). Moreover, as an example, athletes' use of or refraining from use of caffeine pills (Table A1) exemplifies how the athlete group (particularly endurance athletes) have engaged with a previously prohibited substance (prohibited before 2004 in doses above $12 \mu \mathrm{g} / \mathrm{ml}$ ). This corroborates the results that a majority of the athletes would not be interested in using less performanceenhancing products even if legalised (Figure 1).

Explanations for some athletes' lack of interest in strongly performance-enhancing drugs or diet medicines were found in the studies, showing that some athletes feel that good results and changes in body composition (e.g. reduction of weight, body trimming) should be earned through hard work, i.e. through strict training regimes and appropriate diet (Overbye, 2013; Overbye et al., 2013; Rasmussen, 2012), and would prefer to know that they - and not a drug - are responsible for good performance (Overbye, 2013). In this respect, some athletes perceive specific drugs or specific effects of drugs as less acceptable 'shortcuts'. The route of ingestion may also influence athletes' interest: for example, some may dislike or fear injections (Christensen, 2005; Lopez, 2017). A further explanation may be that 'the competition logic' 
(Tangen, 2004) was not explicitly or sufficiently presented in the methodological design of this study: i.e. if their competitors decide to start using very effective performance-enhancing drugs, athletes might need to react if they wish to retain their position. And sporting networks, clubs or organisations may encourage or even demand their use in this situation. Thus, when athletes reported their reflections on which substances they would be interested in trying, they may not have considered the possible dilemma that would occur if 'doping' was in fact legalised. Furthermore, the questions were not linked to a specific situation/social context other than that the specific (named) drug was permitted and qualified medical supervision was assured. Considering the multiple circumstances acting as incentives and protective factors for 'doping' when it is prohibited (Erickson, McKenna, Backhouse, 2014; Overbye et al., 2013), particularly situations in which the athletes' sporting career and future employment are at risk (e.g. injuries) may induce a greater proportion of athletes to use specific drugs if legalised and medically supervised.

Other explanations may involve a fear of the side-effects of the drugs taken (cf. Figure 2; Table A2) or strongly internalised anti-doping norms and values that regard taking AAS and EPO, for example, as cheating, dangerous and something that fundamentally contradicts what sport is about (see WADA, 2015). In line with this, it could be argued that athletes' (internalised) cultural scripts (Rhodes \& Bivol, 2012) reflecting social values on drug use may influence their responses. Here, athletes may not personally feel that they have made judgements on drugs when answering the question. In addition, even if removing the illegal aspect of 'doping' would decrease the sensitivity of the question some responses could be interpreted as socially desirable answers (Petróczi \& Haugen, 2012).

The questions aim to measure micro level responses and considerations from athletes in the situation of legal, medical supervised, 'doping'. Agreement between athletes' answers (Figure 1) and their practices and preferred reactions with regard to less performance-enhancing legal products (cf. previous section; Table A1) suggests that athletes could relate to the question/situation with regard to less performanceenhancing products. But particularly those athletes who did not encounter 'doping' in their close proximity and/or who refrained from using a variety of legal products (Table A1; Overbye, 2013:123) might have found it difficult to imagine the use of EPO, AAS and GH. 
The study design cannot predict whether athletes will indeed react in the way they say if a specific substance was in fact legalised. However, the understanding of elite sport as an exceptional and risky environment (cf. the conceptual framework) suggests that the athletes' 'real life' responses to different drug use will be influenced by not only the specific social and cultural context but also the complex interactions and interdependencies at different levels of the sport figuration. In this context, athletes may change preferred reactions to different drugs or be forced to do so to cope with the (new) working conditions.

\section{The impact of gender, age and type of sport}

A further main finding relates to the great differences within the athlete group, showing that interest in trying specific substances often varies significantly according to athletes' gender, age and type of sport. A relatively large proportion of male athletes in this study who were older, and particularly those from sports which would benefit from a particular substance, were interested in trying EPO or AAS if legal and provided with qualified medical supervision. Female athletes (of all ages) and in particular those from motor-skill sports, on the other hand, were less likely to show interest in very effective performanceenhancing drugs/methods - although interest among female athletes likewise varied according to sports type and increased with the age of the athlete. The gender difference was expected as several studies have suggested that male athletes are more likely than female athletes: i) to be open towards or use doping (Alaranta et al., 2006; Lucidi et al., 2008; Pitsch \& Emrich, 2012); ii) to be curious about how 'doping' can enhance their performance and to have personally explored whether legal substances might enhance their performance (Overbye, 2013); and iii) to disagree that they do not want to achieve a great performance-enhancing effect induced by a drug (Overbye et al., 2013).

The finding that interest in trying a specific substance often increased with the age of athletes of both genders collaborates the findings of other studies (Brissonneau, 2010), and that 'older' athletes were more likely to regularly consume a variety of legal performance-enhancing products (Overbye, 2013) and to (hypothetically) consider using illicit drugs if these could help reduce the damage to the body caused by elite sport or would ensure a faster return to sport after illness (Overbye et al., 2013). 
In keeping with the notions put forward by Alaranta et al. (2006) an important finding of relates to differences between types of sports, which showed predictable patterns of interest, particularly among male athletes. In particular, athletes from the type of sport that would benefit most from a specific substance were also more likely to be interested in that substance. The results confirm the notion that the use of legal and illegal substances in sport may often be understood as a means to an end and not an end goal (Petroczi \& Aidman, 2008). Thus, the results suggest that legalisation of 'doping' or of specific products are likely to have a varying impact in each sport discipline. Moreover, legalising 'doping' (or drugs with a great performance-enhancing and potentially health-damaging impact) would create a larger gap between athletes who might want or dare to use AAS, GH or EPO, for example, and those who do not wish to or are afraid to do so.

A functional use of drugs also implies that some of the athletes who currently use 'doping' may not particularly enjoy this practice but may have engaged in 'doping' to respond to a particular working environment, which, in turn, suggests that the context (i.e. the working conditions and local environment) needs to be altered if 'doping'/drug prevention and the minimising of harms is to be sustainable (Aubel \& Ohl, 2014; Bette, 2004; Overbye, 2013). Consequently, while legalising or partly legalising 'doping' together with harm reduction measures may offer a better chance of protecting doping athletes' health, it seems little likely that all athletes (doping and non-doping) would appreciate a legalisation of 'doping' (Valkenburg et al., 2014; Fürhapter el al., 2015; Stamm et al., 2008). Furthermore, the guarantee of a 'safe environment' is challenged by the 'competition logic' (Tangen, 2004) as well as the particular demands and the characteristics of the elite sport figuration.

\section{Considerations of side-effects if 'doping' was legalised under medical supervision}

The second set of questions addressed the question of whether athletes considered side-effects. An important finding was that the assurance of having a drug provided under qualified medical supervision did not remove a majority of the athletes' fear of side-effects.

The finding that one third of the athletes did not think of side-effects when reflecting on drug use corroborates results of other studies (Kirby et al., 2011; Lentillon-Kaestner \& Carstairs, 2010; LentillonKaestner, Hagger \& Hardcastle, 2011). Yet these results seem surprising, considering that information 
about health risks are embedded in most anti-doping literature/ education programmes/ campaigns (e.g. WADA, 2016) and that substances may be included on the Prohibited List because of their actual or potential health-damaging effects (WADA, 2015). One explanation might be that athletes had not yet faced the situation in which they felt they needed to consider whether or not there were side-effects because they i) seldom or never answered affirmatively; or ii) they just did not consider using those substances commonly linked to health risks (AAS, EPO and GH). If 'doping' were legalised, however, these athletes might need to make a decision for or against using certain drugs, particularly if they compete in a sport in which 'doping' makes a great difference to performance and they wish to maintain their position. If so, the number of athletes who may worry about side-effects is likely to increase.

On the other hand, if the health side-effects of, for example, AAS, EPO and GH are overestimated or at least not properly based on evidence (Coomber, 2014; Kayser \& Broers, 2015) - legalisation, combined with conveying this information to athletes and providing medical guidance, may lower the number of athletes who worry about side-effects. Previous studies, however, suggest that athletes consider health side-effects as a reason for refraining from 'doping' (e.g. Backhouse et al., 2013; Bloodworth \& McNamee, 2010; Gucciardi et al., 2011; Strelan \& Boeckmann, 2006; Overbye et al., 2013), and although many athletes believe that the health side-effects of 'doping' are exaggerated on purpose to scare athletes (Overbye, 2013), the fear of health side-effects related to certain drugs seems to be internalised among a high proportion of the athletes surveyed. A female endurance athlete confirms this when elaborating on her fear of hormones and any drugs that may change or damage the body (see the quotation concerning 'fear of hormones'). Similarly, a male motor-skill sport athlete stated that his health was more important than his sport and that he was unwilling to run health risks induced by a drug (cf. quotation 'unwilling to run health risks'). A recent study has found that past use of AAS increases the risk of Systolic Hypertension in men years after they have stopped using them (Rasmussen et al., 2016). Particularly (and unsurprisingly) the prospect of long-term permanent damage to the body seems to frighten many athletes (see Table A2; quotation 'fear of permanent damage').

One important finding was that a majority of athletes who feared side-effects reported that their fear kept them from wanting to try one or more of the substances/methods listed, although one in five would be interested in trying substances despite the fear of their side-effects. This finding suggests that the 
legalisation of 'doping' would induce a greater number of athletes to use those drugs whose side-effects they fear. These findings illustrate why arguing for legalisation based on the view that athletes are free to choose not to dope (Tamburrini, 2007) and that legalisation would put athletes on a par with doping athletes (Savulescu et al., 2004) seems less convincing when elite sport is perceived as an exceptional and risky working environment and the focus is on seeking to protect occupational health and well-being. Furthermore, the results suggest that refraining from using drugs may relate to a concrete fear of sideeffects, and not necessarily to personal moral beliefs which condemn drugs.

In general, the results corroborate the findings of other studies suggesting that many athletes are unwilling to run severe health risks in order to guarantee sporting success (e.g. Bloodworth \& McNamee, 2010; Bloodworth et al., 2010; Connor et al., 2013; Overbye et al., 2013; Wulff et al., 2016). Yet studies also reveal that quite a large number of athletes show interest in a very effective performance-enhancing drug if its use is not associated with serious health risks (Connor et al., 2013) or if a drug is provided with qualified medical supervision and its use may reduce damage to the body caused by strenuous training, competitions or injuries (Overbye et al., 2013). Access to qualified medical supervision seems to be of great importance (Overbye et al., 2013), and it is commonly expected that qualified medical supervision will reduce the side-effects of drugs (Kayser et al., 2005; Savulescu, 2015; Steward \& Smith, 2015). The prospect that doctors (and support personnel) will act in the best interest of the athletes' health and will be able to decide cases in which drugs can or cannot be used seems to be a presumption in some of the suggestions in new drug-control policies (Savulescu, 2015; Steward \& Smith, 2015). Key questions are whether qualified medical supervision can be assured; whether doctors act in what they believe to be the best interest of athletes; whether there is consensus among doctors about best practices; and, for example, what doses would be appropriate. These questions were brought up by a male team sport athlete who pointed out that the lack of knowledge of and disagreement among doctors made him distrust doctors (cf. quotation 'lack of trust in doctors'). By contrast, a high degree of trust in medical supervision was reported by another male team sport athlete (cf. quotation 'trust in doctors') who felt that correct supervision would make him more confident to use some of the substances, even though he thought that some might have serious side-effects. 
Agreeing to drug use only under specific conditions - e.g. as a reaction to circumstances posing a threat to a sporting career (Bette, 2004; Hauw \& Bilard 2012; Overbye et al., 2013) was exemplified by a female team sport athlete who stated that she would only use some of the listed substances if she was troubled with injuries or her diet (cf. quotation 'drugs if needed'). On the other hand, a male team sport athlete seems to have internalised the competition logic as well as the common norms of elite sport, and expected other athletes to think like him, i.e. the legalisation of 'doping' would lead everyone to 'dope' in order to play sport at a high performance level although it was dangerous (cf. quotation 'competition logic and accepting risks').

The results of the current study, however, suggest that athletes act in different ways and that it is unlikely that all athletes will adhere to the 'competition logic' (Tangen, 2004) when it comes to potentially very effective performance-enhancing drugs such as EPO, AAS and GH. ${ }^{6}$ Similarly, athletes report differently about how they would react to competitors' use of legal performance-enhancing medicines and how (if) coaches or sporting organisations views have an impact on their use (Overbye, 2013:141; Table A1), whether they would evaluate their competitors' doping (when prohibited) as an incentive (Overbye et al., 2013) and if they would be willing to compete hurt in the work context of elite sport (Mayer \& Thiel, 2016). Furthermore, if severe health risks are anticipated, this would prevent many athletes (cf. Figure 2) from reacting by using the same drug, thus adding a dimension of unpredictability to the 'game' of legalised, medically supervised 'doping'.

From the preceding it can be seen that the legalisation of 'doping' in the risky working environment of sport is likely to influence working conditions and occupational health. The following section will interpret the implications of results in a broader perspective, discussing whether (and when) legalising specific 'doping' substances under medical supervision might create a desirable trade-off of harms when focus is placed on protecting athletes' working environment and their occupational health - and understanding sport as an exceptional and risky working environment (cf. the conceptual framework).

\section{An (un)desirable trade of harms?}

One important notion with regard to the 'trade of harms and benefits' is the perspective that anti-doping (the control system) creates problems larger than those solved (e.g. the harms from actually consuming 
doping substances) (Kayser \& Broers, 2012; 2015) and that the focus ought to be placed on minimising health risks for drug users rather than punishment. This paper argues that the impact of 'doping' on the working environment and on the occupational health of all athletes must also be considered a key factor.

Thus, to evaluate the implications of the results some key, and interrelated, questions must be considered - questions relating to the extent to which athletes' working conditions, external pressures and occupational risks may change if a specific drug/method is legalised. The impact/change may depend on: the causation, reduction or change of 'individual' and 'social' harms (which may relate to the possible impact on the prevalence of a specific drug); whether the drug significantly enhances performance levels in the athletes' particular sport; its impact on health; and whether qualified medical supervision can be guaranteed. At the same time, the analysis must seek to distinguish between harms arising from drug use and those caused by the drug control system itself.

\section{Prevalence}

The analysis suggests that that legalisation of substances such as AAS and EPO is likely to significantly increase their use (cf. previous sections). Each year, while fewer than $2 \%$ of doping tests show positive test results (WADA, 2016), studies estimate a significantly higher prevalence of 'doping' among specific athlete groups (de Hon et al., 2010; Pitsch \& Emrich, 2012; Striegel, Ulrich \& Simon, 2010). Despite great unpredictability inherent in the 'game' of legalised medically supervised 'doping' (cf. previous sections; the conceptual framework) and in predicting 'real life' responses to drug uses, it seems plausible to assume that removal of the illegality aspect of 'doping', accompanied by qualified medical supervision, is likely to be decisive for athletes' interest (for example, for the $20 \%$ of male and $3 \%$ of female athletes who reported most likely to be interested in trying AAS if permitted and provided under qualified medical supervision).

\section{Performance-enhancing effect}

Whether a drug/method significantly enhances performance levels in an athlete's particular sport may contribute knowledge about whether or not legalisation (or the legalisation of specific drugs) may create additional pressures on other athletes and their environment (cf. Elite sport an occupation with 
endogenous and exogenous risks). WADA's Prohibited List contains more than 300 substances/methods (WADA, 2017), and their performance-enhancing impact varies between sports (de Hon, 2016). Thus, drawing clear conclusions on the harm causation/reduction of 'doping' is a difficult task and beyond the scope of this article. However, the current study covers different scenarios by introducing both substances/methods with the greatest potential to enhance performance levels (in most sports) and a selection of products/effects with some or little performance-enhancing impact (some of which may potentially improve athletes' health in certain situations). Hence, the study illustrates the large difference in impact of legalisation depending on the particular drug/method (and type of sport), as exemplified below in the cases of EPO and respiratory dilators.

The survey results indicate that athletes in general would prefer not to use EPO. Therefore, allowing EPO up to a specified haematocrit limit while monitoring its use and impact on health (Kayser \& Tollener, 2017; Savulescu, 2015) is likely to create new forms of inequalities between athletes and to put additional pressure on the majority of athletes, who currently either would prefer not to enhance performance with EPO or are afraid to do so. The situations in which a great majority of athletes already use EPO constitute a different case. Although it is uncertain whether legalisation and provision under medical supervision will reduce overall harms, implementing harm minimisation strategies are likely to reduce harms in the case of individual athletes using EPO (Kayser \& Tollener, 2017; Savulescu, 2015), and to be an more efficient doping approach when it matches the athletes behaviour towards doping and injection use (LentillonKaestner, 2015b). However, considering the results of this study, the great majority of athletes - in particular younger athletes and female athletes - are likely to suffer if EPO has a significant performanceenhancing impact in their sport and is permitted and provided under medical supervision.

Legalising respiratory dilators, e.g. common asthma medicines, may have a different impact on athletes' working environment. Relatively few of the surveyed athletes without diagnosed asthma or experience of asthma symptoms (19\%) would be interested in trying respiratory medicines if permitted. Considering, firstly, this result and its implications; secondly, that common medications like inhaled glucocorticoids (Kuipers et al., 2008) and beta2-agonists (Pluim et al., 2011) cannot be proven to enhance physical performance in regular doses; and, thirdly, the obstacles for current TUE administration (Bourdon et al., 2015; Overbye \& Wagner, 2013), de Hon's (2016) appeal that administrators take a close 
look at some of these products and change the way they are regulated within the anti-doping framework would seem a plausible solution that is likely to relieve more harms that it produces.

At a micro level, the results suggest that the legalisation of very performance-enhancing 'doping' substances may have an impact on power dynamics in training environments where good results/performance determine who has most influence, who will get most attention from the coach, and where social norms involve showing a willingness to make sacrifices for the sport (Table A1; cf. Elite sport an occupation with endogenous and exogenous risks). An increase in work-related stress and dilemmas is likely to occur in the case of athletes who are unwilling to use, or worry about using, AAS, GH and EPO (Figures 1 and 2; Table A2), or are unwilling to use these systematically, and who simultaneously believe in these drugs' great capacity to enhance performance levels in their sport (cf. Table 1). This would compound the stress already experienced by a considerable number of athletes operating in a working environment in which worries about the possible social, sporting and financial consequences of not performing as expected are frequently experienced (Overbye, 2013:110).

\section{Health}

Knowing about the side-effects of substances and methods may contribute knowledge not only about whether athletes may be forced into running additional health risks but also about whether legalising some drugs under medical supervision may sometimes reduce health risks in elite sport. The health impact of drugs on the Prohibited List will vary; and the examples provided in this article illustrate the complexity. Many substances on the Prohibited List are medicines which may help individuals to regain health when having a medical need. However, it seems plausible to assume that the effects of drug consumption on health will greatly depend on dosage, frequency of use, route of entry and whether it is single or poly drug use (Coomber, 1999). Thus, the impact may depend on whether the drugs can be monitored and kept within 'safe' doses in the context of sport. Furthermore, the results of this study show that if severe health risks are anticipated, many athletes would tend not to use the drug (Figure 2). Thus, when considering the well-being of athletes, it is essential to take into account the majority of athletes feared side-effects as well as those athletes who - despite fearing side-effects - would be willing to use a drug if it was legalised and provided under medical supervision. 


\section{Qualified medical supervision}

Whether qualified medical supervision can be ensured in a sporting context is essential for reducing drug harm. An important challenge in this respect is posed by the working conditions and by the expectations various groups and individuals have of doctors who work with athletes (Anderson \& Jackson, 2013; Holm et al., 2011; Waddington, 2015). Pressures and demands may vary depending on whether the doctor is employed by a private club or a sports organisation or is a general practitioner (Holm, McNamee, \& Pigozzi, 2011; McNamee \& Phillips, 2011) and may sometimes lead them to compromise professional standards (Andersen \& Jackson, 2013) with less focus on protecting athletes' health (e.g. Roderick, 2006a; Waddington \& Roderick, 2002). Furthermore, the variations in doctors' diagnosis and prescription practices (Tshcoll \& Dvorak, 2012) suggest that 'best practices' with regard to medical supervision may vary greatly between doctors and possibly between continents.

Beyond the aspect of the 'culture of risk' and athletes' interdependence with other actors in the elite sports figuration who likewise may be judged by (and profit from) athletes' results/performances, it seems unlikely that drug use in elite sport will always be based on well-informed choices by athletes nor that professional medical advice when supervising drug use will always be grounded in a genuine interest in protecting athletes' health. From this perspective, the legalisation of strongly performance-enhancing and health-damaging drugs would add additional risks to an already risky occupation.

Another aspect to be considered if strongly performance-enhancing and health-damaging drugs are permitted relates to differences in the accessibility of drugs, as well as athletes' financial circumstances and how differences in resources may have a great impact on athletes' (and their support networks') opportunities to actually choose the "healthiest" option and have access to qualified medical supervision. In addition, the analysis must consider that harm to athletes' health and wellbeing also arise from the drug control system (anti-doping) (cf. Introduction). Each policy element (i.e. doping controls, whereabouts reporting and the TUE system, as well as the Prohibited List and the sanctioning paradigm) has its own purpose, faces different challenges and, to a varying degree, has unintentionally had a negative influence on the working conditions and wellbeing of a number of athletes. Examples of this influence among some of the athletes' surveyed include negative emotions linked to: i) specific policy elements and how these, for example, induce feelings of being under surveillance or suspicion; invade privacy; reduce joy; increase 
stress and discomfort; cause frustration; arouse feelings of unfairness; are too time consuming; and lead to athletes being confronted with administrative obstacles (Elbe \& Overbye, 2014; Overbye, 2013, 2016; Overbye \& Wagner, 2013, 2014); and ii) athletes' worries or fears of mistakenly committing an antidoping rule violation, which influence some athletes' daily lives and practices and, potentially, health, e.g. when avoiding medicines despite a need (Overbye, 2013).

Taking into account that, despite their negative experience of and low level of trust in the effectiveness and fair implementation of anti-doping policies world wide, a great majority of athletes support or accept anti-doping as a principle, including key measures (e.g. Bourdon et al., 2015; Overbye, 2013, 2016; Overbye \& Wagner, 2013, 2014), and considering the results of the present study interpreted with the understanding of sport as an exceptional and risky working environment (in which legalising certain 'doping' substances under medical supervision might create other/new types of harms without having the capacity to ensure the protection of drug-using athletes' health), the potential for minimising the harms of anti-doping measures must be considered.

\section{Limitations}

This study only surveyed Danish athletes'. It is likely that national context may have an effect on the way in which athletes respond to legalised, medically supervised doping and how side-effects are evaluated. The study does not measure how far the athletes would be willing to go in terms of the doses taken and the frequency. Furthermore, athletes responded to the question with the expectation that the medical supervision would be 'qualified'. Yet 'qualified' medical supervision may - as discussed in this paper - be difficult to ensure in a sporting context, and even doctors may disagree about what this entails.

The article measures neither athletes' attitudes to 'doping' or legalisation per se nor their interest in using specific drugs when prohibited in sport. Athletes' interest in specific products cannot be interpreted as the athlete indicating that they would use the drug if prohibited or that they would wish the drug to be legalised. However, by removing the illegal aspect of 'doping', the risk of socially desirable answers decreases. Thus, the results may provide insights not only into athletes' interest in trying specific substances if permitted, but also into their thoughts about specific, currently prohibited substances. 
The article does not consider (or evaluate) the overall impact of medically supervised 'doping' on society or public health; nor does it inquire into the costs from a societal perspective, which were focal points in some of the studies arguing for a radical change in the current drug control model (Kayser et al., 2007; Kayser \& Broers, 2012; 2015; Kayser \& Tollener, 2017).

\section{Concluding remarks and implications}

Considering the results of this study while viewing elite sport as an exceptional and risky working place suggests that a legalising of strongly performance-enhancing and potentially health-damaging substances under medical supervision might open a Pandora's box of uncertain outcomes, likely to lead to unpredictable games with unintended consequences for a greater number of athletes but without the capacity to truly ensure the protection of drug-using athletes' health. From this perspective, the rules prohibiting 'doping' can be regarded as rules seeking to protect workers' health. Hence, some kind of drug control is needed to seek to protect athletes (workers) from exploitation by their surrounding environment as well as to reduce the magnitude of occupational health risks in an already risky working environment. Although the current drug regulation model faces a great variety of challenges, the solution of permitting strongly performance-enhancing and health-damaging doping substances under medical supervision would create new types of harms for athletes and that this trade-off between harms would be unwanted from the perspective of most athletes. Therefore, if the aim is to protect health and secure fairer competition for athletes in general, the legalising of certain 'doping' substances under medical supervision seems to be an inappropriate strategy.

However, not all prohibited substances are performance enhancing and issues of health in relation to some drugs and their impact on working conditions are ambiguous, and this complexity calls for a reconsideration of anti-doping policies, in particular the Prohibited List. All stakeholders involved in antidoping should question whether the limits set today, along with the rationales behind including substances and methods in WADA's Prohibited List remain appropriate and whether the inclusion of specific substances/methods might increase harms. A stronger emphasis on reducing the negative effects and harms of the current drug model, for example, actively seeking to minimise the negative effects of antidoping on athletes' wellbeing and health should be considered. 
To reduce drug-related harms in sport and minimise harms associated with the Prohibited List (e.g. the high number of unintentional doping cases), those composing the Prohibited List could draw to a greater degree on an assessment and differentiation of the individual and social harms produced or reduced in the particular working environment of elite sport and within different sport disciplines. Such assessment might be carried out as a multi-criteria decision analysis undertaken by expert groups from relevant fields (Manning, Wong, Ransley \& Smith, 2016; Nutt et al., 2010; van Amsterdam \& van den Brink, 2010), albeit assessing the specific characteristics of individual and social harms in a sporting context with a focus on occupational health and working conditions, and aiming towards a strategy/model most likely to result in a net reduction of harms in the working environment of elite sport.

From this point of departure, and considering the framework (i.e., protection of occupational health and wellbeing and working conditions in a risky working environment) and results of the current study, a simplified matrix may consider prohibiting drugs/methods likely to increase social and individual harms (e.g. strongly performance-enhancing/performance enhancing and potentially health-damaging drugs) in a specific sport. By contrast, drugs which only, or mainly, produce individual harms (e.g. not/scarcely performance-enhancing drugs) may be better dealt with via harm minimisation programmes and prevention measures (such as promoting structural or cultural changes that may reduce demands for certain drugs in sport). Although, in some sports a B-List and a disciplinary system may be required, i.e., if an athlete's use of a none/scarcely performance enhancing drug possess a health/safety risk for other athletes. One implication of this strategy/model would be that a substance would never be considered for inclusion in the Prohibited List just because it is misused in sport but rather considered purely on the basis of available scientific evidence that it (potentially) significantly enhances performance and at the same time may possess a health risk for athletes. ${ }^{7}$

\section{Roles of the funding source}

The research was financed by The Danish Council for Strategic Research (grant number 2101-07-0021). The sponsor has not had any role in study design; in the collection, analysis, and interpretation of data; in the writing of the manuscript; or in the decision to submit the article for publication. 


\section{Notes}

${ }^{1}$ The 'trade-off between harms and benefits' refer to the trade of harm and benefit of the present doping control model/anti-doping system as compared with a system in which 'doping' is legalised under medical supervision when focus is placed on athletes working conditions, occupational health, and wellbeing.

${ }^{2}$ Elite sport can be understood as a working place, not only for professional sports but also athletes pursuing double careers who likewise are required full time engagement, usually involve in contractual agreement with federations/clubs and face performance-related expectations (Mayer \& Thiel, 2016).

${ }^{3}$ Actors (players) in the sports figuration are, for example, elite athletes, sub-elite athletes, junior athletes, age-group athletes, coaches, administrators, sport physicians and other experts, family and peers, clubs, team owners, sports organisations, event organisers, anti-doping authorities, politicians, governmental institutions (e.g. responsible for the national elite support model), the legal system, healthcare, corporate sponsors, fans, drug supply networks, pharmaceutical companies and global media networks.

${ }^{4}$ These features need to be considered when assessing: i) which model for the regulation of drugs in sport is most suitable (or less harmful); and ii) which unique characteristics do individual harms and social harms have in elite sport environments.

${ }^{5}$ For example asthma medicines; diet medicines containing for example Pseudoephedrine or Ephedrine; intravenous infusions and/or injections of more than $50 \mathrm{ml}$ per 6 hour period.

${ }^{6}$ Heuberger et al., (2017) found that rHuEPO treatment enhanced performance in well-trained nonprofessionals in a laboratory-based maximal exercise test leading to exhaustion, but did not improve submaximal exercise test or road race performance. Subsequently several researchers critically commented on the article or the study design (cf. Erythropoietin on cycling performance, The Lancet, Haematology, 4(10), Oct, 2017), for example, the study did not include a pre-test of road race performance, thus, differences in initial performance and in pacing and drafting strategies could not be controlled for (Bejder et al., 2017). Several studies found rHuEPO to significantly enhance performance (e.g. Lundby et al., 2008). The effects of treatment with rHuEPO treatment may not only relate to 
increase in red blood cell mass, but treatment may simultaneously increase recovery speed, have psychological effects on fatigue and motivation, have an effect on skeletal muscle and the immune system and improve lipolysis (Heuberger et al., 2017).

${ }^{7}$ The scientific evidence behind doping in elite competitive sport is rather scarce, partly because it is impossible to do intervention studies with banned substances on elite athletes who are subject to the WADA regulations (Heuberger et al., 2017).

\section{References}

Alaranta, A., Alaranta, H., Holmila, J., Palmu, P., Pietilä, K., \& Helenius, I. (2006). Self-reported attitudes of elite athletes towards doping: Differences between type of sport. International Journal of Sports Medicine, 27, 842846.

Anderson, L. \& Jackson, S. (2013). Competing loyalties in sports medicine: Threats to medical professionalism in elite, commercial sport. International Review for the Sociology of Sport 48(2): 238-256.

Ashenden, M., Gough, C.E., Garnham, A., Gore, C.J., \& Sharpe K. (2011). Current markers of the Athlete Blood Passport do not flag microdose EPO doping. European Journal of Applied Physiology, 111, 2307-2314.

Aubel, O. \& Ohl, F. (2014). An alternative approach to the prevention of doping in cycling. International Journal of Drug Policy 25, 1094-1102

Backhouse, S.H., Whitaker L., \& Petróczi, A. (2013). Gateway to doping? Supplement use in the context of preferred competitive situations, doping attitude, beliefs, and norms. Scandinavian Journal of Medicine and Science in Sports, 23(2):244-52

Bejder J, Nybo L, Sawka MN, Joyner MJ, Nordsborg NB (2017). Erythropoietin on cycling performance, Haematology, 4(10). Lancet Hematology 4(10) e459-e460

Bette, K.H. (2004). Biographical Risks and Doping. In: Doping and Public Policy ed. Hoberman, J and Møller, V. Odense: University of Southern Denmark.

Birzniece ,V. (2015). Doping in sport: effects, harm and misconceptions. Internal Medicine Journal;45(3):239-248.

Bloodworth, A., \& McNamee, M. (2010). Clean Olympians? Doping and anti-doping: The views of talented young British athletes. International Journal of Drug Policy, 21, 276-282.

Bloodworth, A. J., Petróczi, A., Bailey, R., Pearce, G., \& McNamee, M. J. (2012). Doping and supplementation: the attitudes of talented young athletes. Scandinavian journal of science and medicine in sport, 22(2):293-301 
Bourdon, F., Schoch, L., Broers, B., \& Kayser, B. (2015). French speaking athletes' experience and perception regarding the whereabouts reporting system and therapeutic use exemptions. Performance Enhancement \& Health, 3: 153-158.

Brissonneau, C. (2010). An integrationist study of phenomenon of doping (1950-2010). In CERSES. Centre de Recherche Sens, Ethique, Société. Conference presentation: Body enhancements and (il)legal drugs in sport and exercise-Human and social perspectives. Department of Exercise and Sport Sciences, University of Copenhagen, November 10-12.

Christensen, A.V. (2005). Rene resultater: En kulturanalyse af cykelsporten - socialisation, fascination, traning, kost og doping. PhD thesis. University of Southern Denmark

Christiansen, A. V. \& Møller, V., (2007). Mål, medicin og moral - om eliteatleters opfattelse af sport, doping og fairplay. Odense: Syddansk Universitetsforlag.

Cook, C, Bridge, J., \& Stimson, G. (2010). The diffusion of harm reduction in Europe and beyond. In: Harm reduction: evidence, impacts and challenges (eds., Rhodes, T., \& Hedrick, D.). European Monitoring Centre for Drugs and Drug Addiction.

Coomber, R. (2014). How social fear of drugs in the non-sporting world creates a framework for doping policy in the sporting world. International Journal of Sport Policy and Politics, 6(2): 171-193.

Coomber R. (1999). Assessing the real dangers of illicit drugs_risk analysis as the way forward? Addiction Research and Theory, 7(2): 85-90.

Connor, J., Woolf, J., \& Mazanov, J. (2013). Would they dope? Revisiting the Goldman dilemma. British Journal of Sports Medicine, 47, 697-700.

Cox, T.W. (2014). International war against doping: Limiting the collateral damage from strict liability. The Vanderbilt Journal of Transnational Law, 47, 295-329.

Critcher, C. (2014): New perspectives on anti-doping policy: from moral panic to moral regulation, International Journal of Sport Policy and Politics, 6(2), 153-169

de Hon, O. (2016). Striking the Right Balance. Effectiveness of Anti-Doping Policies. PhD thesis. Dopingautoriteit. University of Utrecht.

de Hon, O. \& van Bottenburg, M. (2016) True dopers or negligent athletes - an analysis of anti-doping rule violations reported to the World Anti-Doping Agency 2010-2012. From de Hon, (2016). Striking the Right Balance. Effectiveness of Anti-Doping Policies. PhD thesis. Dopingautoriteit. University of Utrecht. Article II p. 74 
de Hon, O.; Kuipers, H. \& Bottenburg, M. (2015). Prevalence of doping use in elite sports: A review of numbers and methods. Sports Medicine, 45, 57-69. doi:10.1007/s40279-014-0247-x

Dimeo, P., Allen, J., Tayler, J., Dixon, S. and Robinson, L. (2013). Team dynamics and doping in sport: A risk or a protective factor? Report compiled for the World Anti-Doping Agency. Stirling University, Scotland

Dikic, N., Markovic, S.S., \& McNamee, M., (2011). On the Efficacy of WADA's Whereabouts Policy: Between Filing Failures and Missed Tests. Deutsche Zeitschrift für Sportmedizin, 62 (10).

Delanghe, J.R., Bollen, M. \& Beullens, M. (2008) 'Testing for recombinant erythropoietin', American Journal of Hematology, 83, 237-41.

Elbe, A.M., \& Overbye, M. (2014). Urine Doping Controls: The Athletes' Perspective. International Journal of Sport Policy and Politics, 6(2), 227-240.

Elias, N., 1978. What is Sociology? New York: Columbia University Press.

Efverström, A. Ahmadi, N., Hoff, D. \& Bäckström, Å. (2016). Antidoping and legitimacy: an international survey of elite athletes' perceptions, International Journal of Sport Policy and Politics, 8(2): 491-514.

Engelberg,T., Moston, S. \& Skinner, J. (2015). The final frontier of anti-doping: A study of athletes who have committed doping violations. Sport Management Review, 18(2), 268-279.

Erickson, K., McKenna, J., \& Backhouse, S. (2014). A qualitative analysis of the factors that protect athletes against doping in sport, Psychology of Sport and Exercise, 16, 149-155.

Fincoeur B., van de Ven, K. \& Mulrooney, J. D. K (2015). The symbiotic evolution of anti-doping and supply chains of doping substances: how criminal networks may benefit from anti-doping policy. Trends Organ Crim 18:229250

Fry, C. (2017). The case for and against harm reduction approaches to drugs in sport. J Med Ethics, 43 (5):280-281.

Fürhapter, C., Blank, C., Leichtfried, V., Mair-Raggautz, M., Müller, D., \& Schobersberger, W. (2013). Evaluation of West-Austrian junior athletes' knowledge regarding doping in sports. The Central European Journal of Medicine, 125(1-2), 41-49.

Gucciardi, D.F., Jalleh, G., \& Donovan, R.J. (2011). An examination of the Sport Drug Control Model with elite Australian athletes. Journal of Science and Medicine in Sport, doi:10.1016/j.jsams.2011.03.009.

Hanstad, D.V. (2009). Anti-Doping in Sport. A Study of Policy Development since 1998. Dissertation from the Norwegian School of Sport Sciences.

Hanstad, D. V., Skille, E. Å. \& Loland, S. (2010). Harmonization of anti-doping work: Myth or reality? Sport in Society, 13, 418-430. 
Hanstad, D.V., \& Loland, S. (2005). What is efficient doping control?: A study of procedures and their justification in the planning

Hanstad, D. V. \& Loland, S. (2009). Elite athletes' duty to provide information on their whereabouts: justifiable antidoping work or an indefensible surveillance system? European Journal of Sport Science, 9(1), 3-10.

Hanstad, D. V., \& Waddington, I. (2009). Sport, Health and Drugs: a Critical Re-examination of Some Key Issues and Problems. Perspectives in Public Health, 129, 174-182.

Haugen (2011). Kjetil K. Haugen guest blog: Why we shouldn't allow performance enhancing drugs in sport. http://blogs.bmj.com/bjsm/2011/04/21/kjetil-k-haugen-guest-blog-why-we-shouldnt-allow-performanceenhancing-drugs-in-sport

Hauw, D., \& Bilard, J. (2012). Situated activity analysis of elite track and field athletes' use of prohibited performance-enhancing substances. The Journal of Substance Use, 17(2), 183-197

Heuberger J.A.A.C., Rotmans J.I, Gal P., et al. (2017). Effects of erythropoietin on cycling performance of well trained cyclists: a double-blind, randomised, placebo-controlled trial. Lancet Haematology, 4(8). e374-e386

Hoberman, J. (2002). Sports Physicians and the Doping Crisis in Elite Sport. Clinical Journal of Sport Medicine, 12, 203-208.

Holm S (2007). Doping under medical control—conceptually possible but impossible in the world of professional sports? Sports, Ethics and Philosophy, 1(2):135-45.

Holm, S., McNamee, J.M., \& Pigozzi, F. (2011). Ethical practice and sports physician protection: a proposal. British Journal of Sports Medicine, 45, 1170-1173.

Houlihan, B. (2014). Achieving compliance in international anti-doping policy: An analysis of the 2009 World AntiDoping Code, 17(3): Sport Management Review, 17(3)265-276

Kayser, B. \& Broers, B. (2015). Harms and harm reduction. In: V. Moller, I. Waddington \& J. Hoberman (eds.). Routledge handbook of Drugs and Sport, UK, Routledge. p. 363-76.

Kayser, B. \& Broers, B. (2012) 'The Olympics and harm reduction?' Harm Reduction Journal, 9 (33), doi:10.1186/1477-7517-9-33

Kayser, B., Mauron, A., \& Miah, A. (2005). Viewpoint Legalisation of performance-enhancing drugs. Lancet, 366: $\mathrm{S} 21$

Kayser, B., Mauron, A., \& Miah, A. (2007). Current anti-doping policy: A critical appraisal. BMC Medical Ethics, $8(2)$.

Kayser, B. \& Smith, A. C. T. (2008). Globalisation of anti-doping: the reverse side of the medal. British Medical Journal, 33, 85-87. 
Kayser, B. \& Tollener, J. (2017). Ethics of a relaxed antidoping rule accompanied by harm-reduction measures. $J$ Med Ethics, 43(5):282-286.

Kimergaard, A., \& McVeigh, J. (2014). Variability and dilemmas in harm reduction for anabolic steroid users in the UK: a multi-area interview study. Harm Reduction Journal, 11:19

Kirkwood, K. (2009). Considering harm reduction as the future of doping control policy in international sport. Quest, 61:180-90.

Kirby, K., Moran, A. \& Guerin, S. (2011). A qualitative analysis of the experiences of elite athletes who have admitted to doping for performance enhancement. International Journal of Sport Policy and Politics, 3:2, $205-$ 224.

Kuipers H, Van’t Hullenaar, GAC; Pluim, BM; Overbeek, SE; de Hon, O.; van Breda, EJ., \& van Loon, LC (2008). Four weeks of corticosteroid inhalation does not augment maximal power output in endurance athletes. $B r J$ Sports Med,42:868-871

Lentillon-Kaestner V (2013). The development of doping use in high-level cycling: From team-organized doping to advances in the fight against doping. Scand J Med Sci Sports, 23: 189-197

Lentillon-Kaestner, V. (2015a). Doping use and deviance in Swiss national and international elite cycling. Performance Enhancement \& Health 3: 167-174

Lentillon-Kaestner V (2015b) Use of Injections in Amateur and Professional Cycling. J Subst Abuse Alcohol 3(1): 1026 .

Lentillon-Kaestner, V. \& Carstairs, C. (2010). Doping use among elite cyclists: a qualitative psychosociological approach. Scandinavian Journal of Medicine and Science in Sports, 20, 336-345.

Lentillon-Kaestner, V., Hagger, M. S., \& Hardcastle, S. (2011). Health and doping in elite-level cycling. Scandinavian Journal of Medicine and Science in Sports. doi: 10.1111/j.1600-0838.2010.01281.x.

Lippi, G., Banfi, G., Franchini, M., \& Guidi, G. C. (2008). New strategies for doping control. Journal of Sports Sciences, 26, 441-445.

Lopez, B. (2017). From needle phobia to doping phobia: Can the fear of injections help us understand anti-dopism? Drugs: Education, Prevention and Policy, 24(3), 314-320.

Lucidi, F., Zelli, A., Mallia, L., Grano, C., Russo, P. M., \& Violani, C. (2008). The social-cognitive mechanisms regulating adolescents' use of doping substances. Journal of Sports Sciences, 26, 447-456.

Lundby, C., Robach. P., Boushel, R, Thomsen, J.J., Rasmussen, P., Koskolou, M., Calbet, J.A.. (2008). Does recombinant human Epo increase exercise capacity by means other than augmenting oxygen transport? Journal of Applied Physiology, 105:581-7. 
Lundby, C., Achman-Andersen, N.J., Thomsen, J.J., Norgaard, A.M. and Robach, P. (2008) 'Testing for recombinant human erythropoietin in urine: problems associated with current anti-doping testing', Journal of Applied Physiology, 105, 417-19

Lundby, C, Robach, P., \& Saltin, B. (2012). The evolving science of detection of 'blood doping'. British Journal of Pharmacology, 165, 1306-1315.

Mayer, J. \& Thiel, A. (2016). Presenteeism in the elite sports workplace: The willingness to compete hurt among German elite handball and track and field athletes. International Review for the Sociology of Sport. DOI: $10.1177 / 1012690216640525$

Malcolm D (2009). Medical uncertainty and clinician-athlete relations: The management of concussion injuries in rugby union. Sociology of Sport Journal, 26(2):191-210.

Malcolm, D., \& Sheard, K. (2002). "Pain in the Assets": The Effects of Commercialization and Professionalization on the Management of Injury in English Rugby Union. Sociology of Sport Journal, 19, 149-169

Manning, M., Wong, G. T. W., Ransley, J., \& Smith, C. (2016). Analysing pseudoephedrine/ methamphetamine policy options in Australia using multi-criteria decision modelling. International Journal of Drug Policy, 32, 85-92.

Mazanov J. \& Connor, J. (2010). Rethinking the management of drugs in sport. International Journal of Sport Policy and Politics, 2, 49-63.

McArdle, D. (2015). 'Strict Liability' and Legal Rights: Nutritional Supplements, 'Intent' and 'Risk' in the Parallel World of WADA. In: Routledge handbook of Drugs and Sport, (eds. V. Moller, I. Waddington \& J. Hoberman). UK, Routledge, p. 293-209.

McNamee, M., \& Phillips, N. (2011). Confidentiality, disclosure and doping in sports medicine. British Journal of Sports Medicine, 45(3), 174-177.

Moston, S. \& Engelberg, T. (2016). The presumption of guilt relating to athletes accused of doping. World Sports Advocate, 14(12): 8-11.

Møller V \& Dimeo P (2014) Anti-doping - the end of sport. International Journal of Sport Policy and Politics, 6 (2), pp. $259-272$.

Møller, V (2010). The ethics of doping and anti-doping. Redeeming the soul of sport? London/New York: Routledge.

Møller, V. (2011). One step too far - about WADA's whereabouts rule. International Journal of Sport Policy and Politics, 3 (2), 177-190.

Nixon, H. L. (1992). A social network analysis of influences on athletes to play with pain and injury. Journal of Sport \& Social Issues, 16, 127e135 
Nutt, D.J., King, L.A, Phillips, L. D. (2010). Drug harms in the UK: a multicriteria decision analysis. Lancet, 376 : 1558-65

Ohl, F., Fincoeur, B., Lentillon-Kaestner, V., Defrance, J. \& Brissonneau, C. (2015). The socialization of young cyclists and the culture of doping. International Review for the Sociology of Sport, 7:865-882.

Overbye, M. (2017) Deterrence by risk of detection? An inquiry into how elite athletes perceive the deterrent effect of the doping testing regime in their sport. Drugs: Education, Prevention and Policy, 24(2):206-219.

Overbye, M. (2016). Doping control in sport: An investigation of how elite athletes perceive and trust the functioning of the doping testing system in their sport. Sport Management Review, 19 (1): 6-22.

Overbye, M. (2013). Doping og anti-doping i kontekst. En analyse af eliteidrcetsudøveres oplevelse af anti-doping policy, betydende faktorer for til- eller fravalg af doping, (u)lovlige prcestationsfremmende midler, grcenser og dilemmaer. PhD thesis. Department of Nutrition, Exercise and Sports, University of Copenhagen, Denmark.

Overbye, M., \& Wagner, U. (2014). Experiences, attitudes and trust: an inquiry into elite athletes' perception of the whereabouts reporting system. International Journal of Sport Policy and Politics, 3 (6): 407-428.

Overbye, M., \& Wagner, U. (2013). Between medical treatment and performance enhancement: An investigation of how elite athletes experience Therapeutic Use Exemptions. International Journal of Drug Policy. 24 (6), 579 588

Overbye, M., Lykke Knudsen, M., \& Pfister G. (2013). To Dope or Not to Dope: Elite athletes' perceptions of doping deterrents and incentives. Performance Enhancement and Health, 2 (3): 119-134.

Pappa, E. \& Kennedy, E. (2013). 'It was my thought ... he made it a reality': Normalization and responsibility in athletes' accounts of performance-enhancing drug use. International Review for the Sociology of Sport, 48(3), $277-294$

Petroczi, A. \& Aidman, E.V. (2008). Psychological drivers in doping: the life-cycle model of performance enhancement. Substance abuse treatment, prevention, and policy, 3, 7.

Petróczi, A., \& Haugen, K. K. (2012). The doping self-reporting game: The paradox of a 'false-telling' mechanism and its potential research and policy implications. Sport Management Review, 15, 513-517.

Pitsch, W., \& Emrich, E. (2012). The frequency of doping in elite sport: Results of a replication study. International Review for the Sociology of Sport, 47(5), 559-580.

Pluim, B.M (2008). A doping sinner is not always a Cheat. British Journal of Sports Medicine, 42, 549-550.

Pluim, B.M., de Hon, O., Staal, J.B. et al. (2011). $\beta 2$-Agonists and Physical Performance A Systematic Review and Meta-Analysis of Randomized Controlled Trials. Sports Medicine, 41: 39. 
Rasmussen, K. (2012): Cykelsport og askese - en analyse af cykelrytteres livspraksis. Ph.d. thesis. Department of Sport and Exercise Sciences. University of Copenhagen, Denmark.

Rasmussen, J.J., Schou, M., Selmer, C., Faber, J., Gustafsson, F., \& Kistorp, C. (2016). History of Anabolic Androgenic Abuse Is Associated with Increased Risk of Systolic Hypertension. SAT-579: Endocrine Society's 98th Annual Meeting and Expo, April 1-4, 2016 - Boston

Rhodes, T. (2009). Risk environments and drug harms: A social science for harm reduction approach. International Journal of Drug Policy, 20, 193-201.

Rhodes, T. (2002). The 'risk environment': a framework for understanding and reducing drug-related harm. International Journal of Drug Policy 13, 85-94

Rhodes, T. \& Bivol, S. (2012)."Back then" and "nowadays": social transition narratives in accounts of injecting drug use in an East European setting. Social Science \& Medicine 74(3), 425-433

Roderick, M. (2006a). Adding insult to injury: workplace injury in English professional football. Sociology of Health and Illness, 28(1), 76-97.

Roderick, M. (2006b). A very precarious profession: uncertainty in the working lives of professional footballers. Work, employment and society, 20(2): 245-265

Safai, P. (2003) Healing the body in the "culture of risk": Examining the negotiation of treatment between sport medicine clinicians and injured athletes in Canadian intercollegiate sport. Sociology of Sport Journal 20: 127146.

Savulescu, J., Foddy, B., \& Clayton, M. (2004). Why we should allow performance enhancing drugs in sport. British Journal of Sports Medicine, 38, 666- 670.

Savulescu, J. (2015). Healthy Doping: Why We Should Legalise Performance Enhancing Drugs in Sport. In: V. Moller, I. Waddington \& J. Hoberman (eds.). Routledge handbook of Drugs and Sport, UK, Routledge. p. 350362.

Siekmann, R. C. R., \& Soek, J. W. (2010). The Implementation of the WADA Code in the European Union. The Haag: T.M.C. Asser Instituut.

Steward, B. \& Smith, A.C.T (2015). Revisting the drugs-in-sport problem: a manifesto for a new deal. In: V. Moller, I. Waddington \& J. Hoberman (eds.). Routledge handbook of Drugs and Sport, UK, Routledge. p.260-279.

Stewart, B., \& Smith, A. C. T. (2008). Drug Use in Sport: Implications for Public Policy. Journal of Sport \& Social Issues, 32, 278-298.

Smith, C. (2015). Tour du dopage: Confessions of doping professional cyclists in a modern work environment. International Review for the Sociology of Sport, 52(1), 97-111. 
Stamm, H., et al., 2008. The public perception of doping in sport in Switzerland, 1995-2004. Journal of sports sciences, 26 (3), 235-242.

Strelan, P. \& Boeckmann R.J. (2006). Why drug testing in elite sport does not work: perceptual deterrence theory and the role of personal moral beliefs. Journal of applied social psychology, 36, 2909-2934.

Striegel, H., Ulrich, R., \& Simon, P. (2010). Randomised response estimates for doping and illicit drug use in elite athletes. Drug and alcohol dependence, 106, 230-232.

Tangen, J. O. (2004). Hvordan er idrett mulig?: Skisse til en idrettssosiologi. Kristiansand: Høyskoleforlaget.

Tamburrini, T. (2007). Are Doping Sanctions Justified? A Moral Relativistic View. In A.J. Sneider \& F. Hong (eds.), Doping in sport. Global ethical issues. (p.23-35). London: Routledge.

The Lancet Hematology (2017). Erythropoietin on cycling performance, Haematology, 4(10), e459-62

Tscholl, P., Feddermann, N., Junge, A., \& Dvorak, J. (2009). The Use and Abuse of Painkillers in International Soccer: Data from 6 FIFA Tournaments for Female and Youth Players. The American Journal of Sports Medicine, 37(2), 260-265.

Tscholl, P.M., \& Dvorak, J. (2012). Abuse of medication during international football competition in 2010 - lesson not learned. British Journal of Sports Medicine, 46(16), 1140-1141.

Valkenburg, D., Hon, O., \& Hilvoorde, I. (2014). Doping control, providing whereabouts and the importance of privacy for elite athletes. International Journal of Drug Policy. 25 (2), 212-218.

van Amsterdam J. \& van den Brink, W (2010). Ranking of drugs: a more balanced risk-assessment. Lancet, 6;376(9752):1524-5. doi: 10.1016/S0140-6736(10)62000-4.

WADA (2013). Report to WADA Executive Committee on lack of effectiveness of testing programs. Montreal: World Anti-Doping Agency.

WADA (2015). World Anti-Doping Code. Montreal: World Anti-Doping Agency

WADA (2016). ANTI-DOPING TESTING FIGURE. Available at: https://www.wadaama.org/sites/default/files/resources/files/2015_wada_anti-doping_testing_figures_report_0.pdf [accessed $25.6 .2017]$

WADA (2017). World Anti-Doping Code. International Standard. Prohibited List. Montreal, Canada: World AntiDoping Agency.

Waddington, I. (2015). Towards an understanding of drug use in sport. A medical sociological Perspective. In: V. Moller, I. Waddington \& J. Hoberman (eds.). Routledge handbook of Drugs and Sport, UK, Routledge. 405 417.

Waddington, I. (2000). Sport, Health and Drugs: A Critical Sociological Perspective. London: E. \& F.N. Spon. 
Waddington, I. (1996). Development of Sport Medicine. Sociology of Sport Journal, 13, 176-196.

Waddington, I. \& Smith, A. (2009). An introduction to drugs in sport. Addicted to winning? Oxon, UK: Routledge.

Waddington, I. (2010). Surveillance and control in sport: a sociologist looks at the WADA whereabouts system. International Journal of Sport Policy and Politics, 2, 255-274.

Waddington, I., \&, Roderick, M. (2002). Management of medical confidentiality in English professional football clubs: some ethical problems and issues. British Journal of Sports Medicine, 36, 118-123.

Wagner, U. (2009). The struggle for clean sports. Ph.d. thesis. Department of Sport and Exercise Sciences. University of Copenhagen, Denmark.

Wagner, U. (2010). The International Cycling Union under Siege - Anti-doping and the Biological Passport as a Mission Impossible? European Sport Management Quarterly, 10 (3), 321-342.

Wagner, U., \& Hanstad, D. V. (2011). Scandinavian perspectives on doping: a comparative policy analysis in relation to the international process of institutionalizing anti-doping. International Journal of Sport Policy, 3, $355-372$.

Wulff, J., Mazanov, J, \& Connor, J.M. (2016). The Goldman Dilemma is dead: what elite athletes really think about doping, winning, and death. International Journal of Sport Policy and Politics. http://dx.doi.org/10.1080/19406940.2016.1194875 
Table 1: Participants' characteristics

\begin{tabular}{|c|c|c|c|c|c|c|}
\hline \multirow[t]{2}{*}{$\mathrm{N}=775$} & & \multirow[t]{2}{*}{ Total } & \multicolumn{4}{|c|}{ Sport type } \\
\hline & & & Team sports & $\begin{array}{c}\text { Speed and } \\
\text { power sports }\end{array}$ & $\begin{array}{l}\text { Endurance } \\
\text { sports }\end{array}$ & $\begin{array}{l}\text { Motor-skill } \\
\text { sports }\end{array}$ \\
\hline \multicolumn{2}{|l|}{ Sport type } & $100 \%$ & $48 \%$ & $23 \%$ & $18 \%$ & $11 \%$ \\
\hline \multirow{2}{*}{ Gender } & Male & $60 \%$ & $57 \%$ & $66 \%$ & $66 \%$ & $57 \%$ \\
\hline & Female & $40 \%$ & $43 \%$ & $35 \%$ & $34 \%$ & $43 \%$ \\
\hline \multicolumn{2}{|l|}{ Mean age (SD) } & $21.73(5.56)$ & $20.94(4.88)$ & $22.17(5.86)$ & $22.22(5.42)$ & $23.44(7.23)$ \\
\hline \multirow{3}{*}{$\begin{array}{l}\text { Years at elite } \\
\text { level }^{a}\end{array}$} & $\begin{array}{l}\text { Less than } 4 \\
\text { years }\end{array}$ & $36 \%$ & $39 \%$ & $29 \%$ & $35 \%$ & $38 \%$ \\
\hline & $4-8$ years & $36 \%$ & $36 \%$ & $38 \%$ & $41 \%$ & $26 \%$ \\
\hline & $\begin{array}{l}9 \text { years or } \\
\text { longer }\end{array}$ & $28 \%$ & $25 \%$ & $33 \%$ & $24 \%$ & $36 \%$ \\
\hline \multicolumn{2}{|c|}{$\begin{array}{l}\text { Competed in the World } \\
\text { Championships or Olympics }\end{array}$} & $58 \%$ & $39 \%$ & $72 \%$ & $74 \%$ & $79 \%$ \\
\hline \multirow{3}{*}{$\begin{array}{l}\text { Athletes' beliefs } \\
\text { that AAS, GH or } \\
\text { blood doping } \\
\text { would have an } \\
\text { effect in their }^{\text {sport }}{ }^{c}\end{array}$} & $\begin{array}{l}\text { AAS } \\
\text { (great effect) }\end{array}$ & $83 \%(26 \%)$ & $88 \%(28 \%)$ & $91 \%(32 \%)$ & $88 \%(28 \%)$ & $40 \%(4 \%)$ \\
\hline & $\begin{array}{l}\text { GH } \\
\text { (great effect) }\end{array}$ & $84 \%(22 \%)$ & $90 \%(25 \%)$ & $89 \%(30 \%)$ & $86 \%(19 \%)$ & $44 \%(2 \%)$ \\
\hline & $\begin{array}{l}\text { Blood doping } \\
\text { (great effect) }\end{array}$ & $81 \%(25 \%)$ & $86 \%(12 \%)$ & $76 \%(13 \%)$ & $96 \%(74 \%)$ & $46 \%(4 \%)$ \\
\hline
\end{tabular}

${ }^{a}$ The number of years at elite level was calculated from the year the athletes reported that they were first selected for a national team training squad or an international competition by their federation.

${ }^{\mathrm{b}}$ Competed once or more at a the World Championship or the Olympics as a junior and/or in the elite category

${ }^{c}$ Note: these numbers are based only on the answers from the participants $(71 \%, n=549)$ who participated in the current study and another survey assessing how athletes perceive doping and antidoping efforts (Overbye, 2013).The percentage illustrates the share of athletes who believe that AAS, $\mathrm{GH}$ and blood doping (respectively) have an effect (great effect, some effect or little effect) in their sport. The numbers in parentheses refer only to the percentage of athletes who regard the substance to have a "great effect" in their sport. 


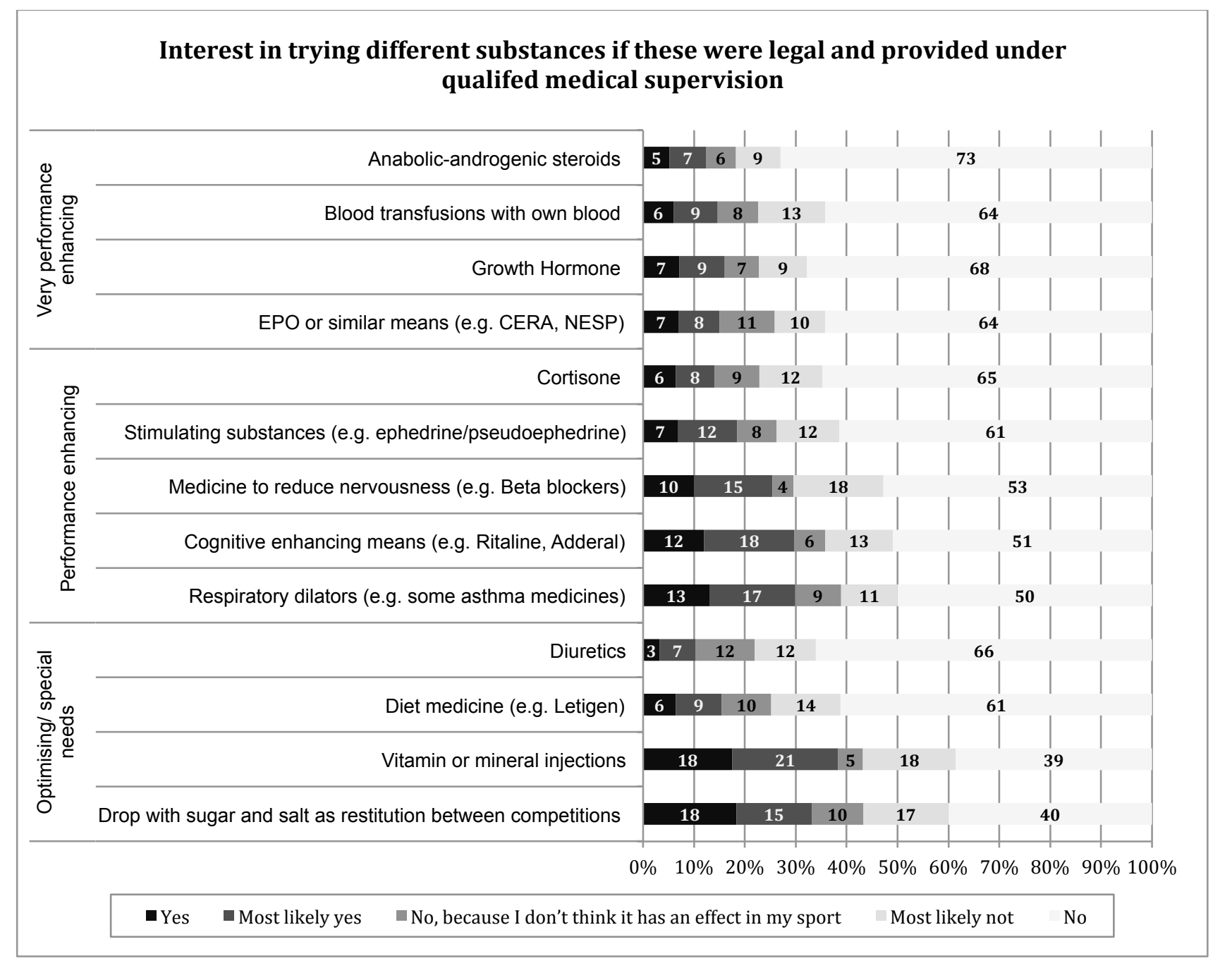

Figure 1: The substances/methods athletes would be interested in trying if these were legal and could be provided under qualified medical supervision.

Note 1: $60 \%(n=55)$ of the 93 athletes in the current study diagnosed with asthma answered yes or most likely yes to the use of "Respiratory dilators (e.g. some asthma medicines)". In contrast, only $19 \%$ of the athletes who were not diagnosed asthma (and who had not experienced any asthma symptoms) would most likely be interested in respiratory dilators if permitted in sport.

Note 2: The respondents were not informed about the potential performance-enhancing impact (which will vary according to sports type). The categorisation of products was carried out by the author and relates to: i) the products' classification on the prohibited list, i.e. specified vs. non-specified substances; the status of prohibition, i.e. prohibited at all times, only in-competition or in some sports; and ii) evidence about performance-enhancing effects regarding EPO, blood transfusions, AAS and GH (e.g. Lundby et al., 2008; Birzniece, 2017).

Very performance enhancing: these are all non-specified substances/methods, prohibited at all times: AAS (S1); growth hormone (S2), EPO (S2) and blood transfusions (M1).

Performance enhancing: Cortisone: prohibited when administered by oral, intravenous, intramuscular or rectal routes (specified: S9); stimulating substances, e.g. Ephedrine (prohibited in competition: specified S6a; non-specified: $\mathrm{S6b}$ ); beta blockers: prohibited in competition and out of-competition in particular sports (specified: P2); cognitive enhancing means, e.g. Ritaline (specified: S6b); respiratory dilators (e.g. S1, S3; specified and non-specified, inhaled).

Optimising/special needs: diuretics [specified; S5]; diet medicines, some diet medicines can contain prohibited substances (e.g. non-specified S6a; specified S6b thresholds); intravenous infusions and/or injections: prohibited if injection exceeds more than $50 \mathrm{ml}$ per 6 hour period (prohibited at all time, non-specified, M2). 


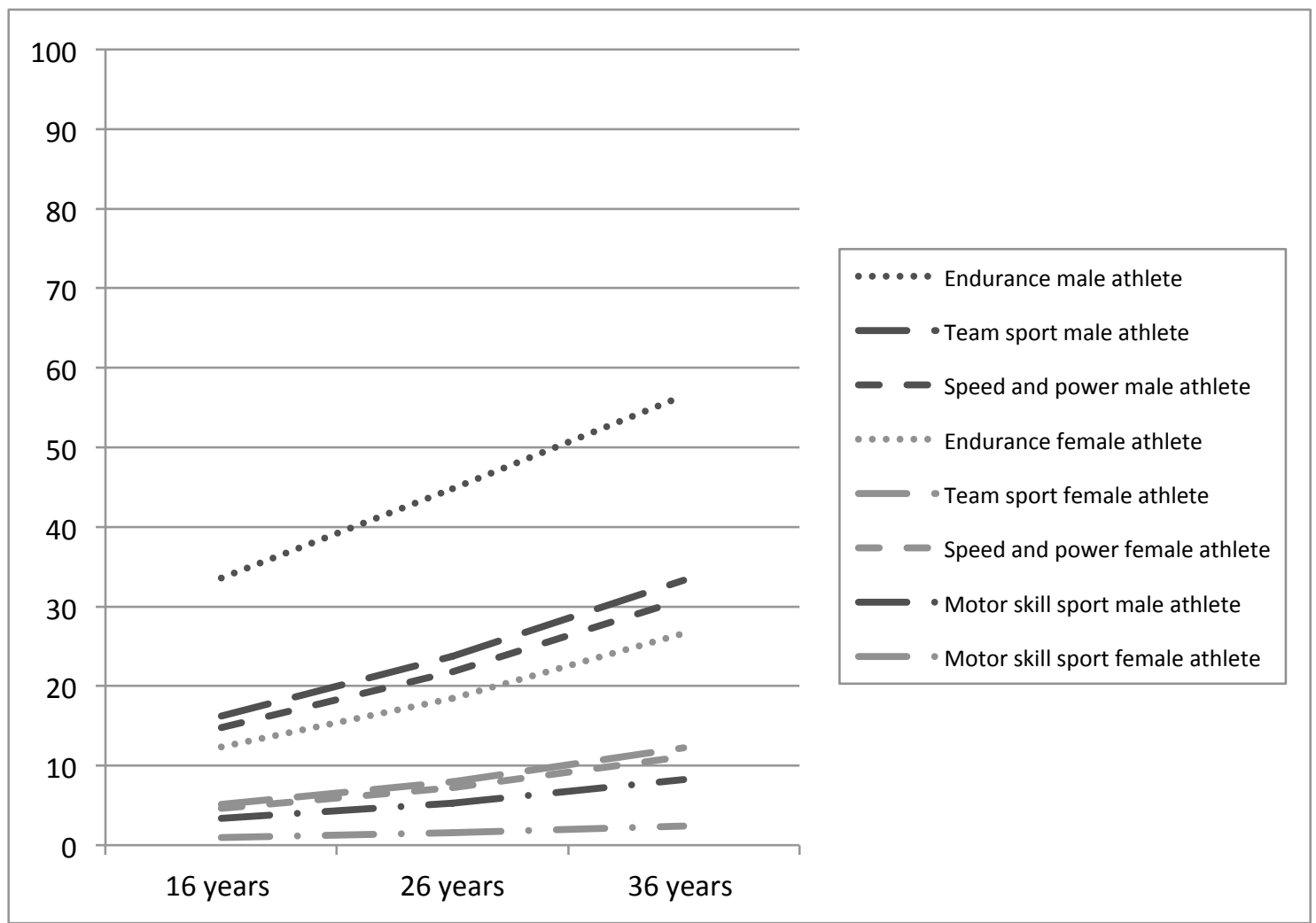

Figure 2: The probability that an athlete would be interested in trying EPO or similar medicines (e.g. CERA, NESP) if legal and provided under qualified medical supervision according to gender, age and type of sport. Calculated from the final logistic regression model. 


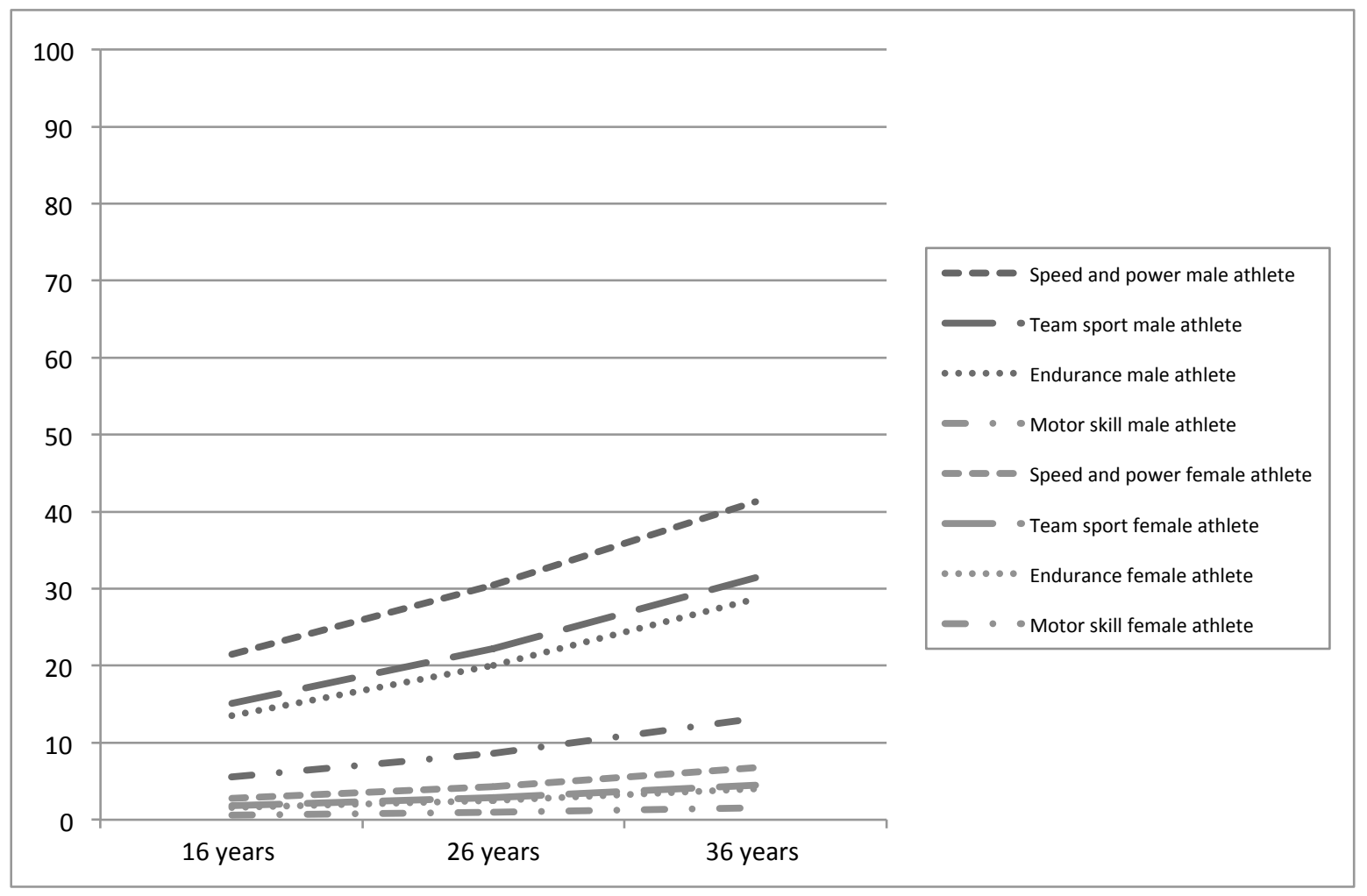

Figure 3: The probability that an athlete would be interested in trying AAS if legal and provided under qualified medical supervision according to gender, age and type of sport. Calculated from the final logistic regression model. 


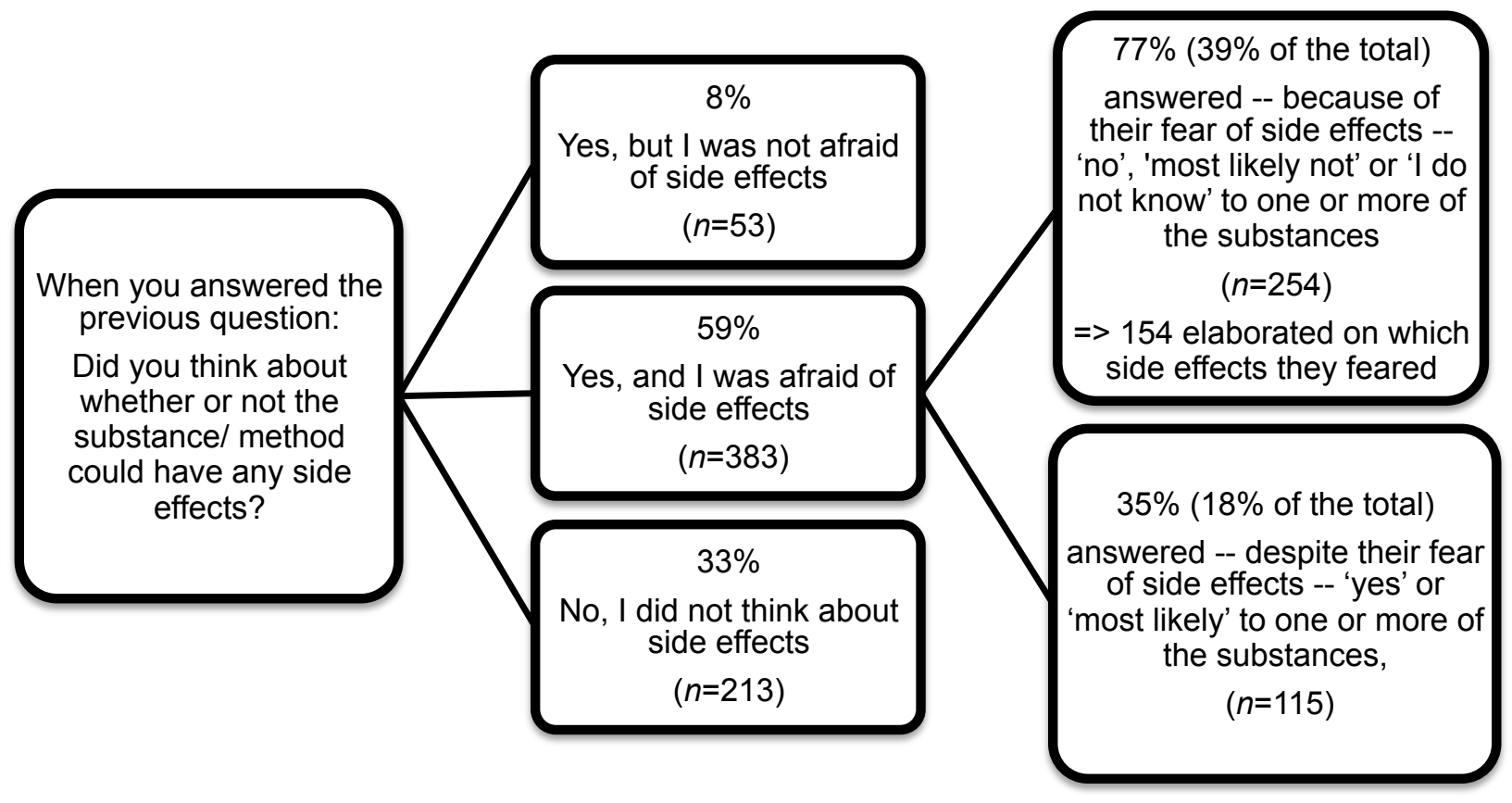

Figure 4. Athletes' considerations of side-effects if 'doping' was legal and provided under qualified medical supervision and how a fear of side-effects has an impact on athletes' interest in drugs. No differences were found between athletes of different genders, age group or type of sport.

Note: The impact of side-effects on athletes decisions can depend on the specific substances/methods. Therefore, athletes can answer they would refrain from one or more substances because of their fear of side-effects in relation to these, however, at the same time, chose not to refrain from another/other substance(s) despite fearing side-effects. 
Table A1: Contextualisation: Patterns of sport-related use of legal products, doping proximity, competition logic and the environment $\mathrm{N}=775$ Total Sport type

$\begin{array}{rrrr}\text { Team sports } & \begin{array}{r}\text { Speed and } \\ \text { power sports }\end{array} & \text { Endurance } & \text { Motor-skill } \\ \text { sports } & \text { sports }\end{array}$

Patterns of sport-related use of selected legal products ${ }^{a}$

(prohibited in sport before 2004 in doses $>12 \mu \mathrm{g} / \mathrm{ml}$ )

Additional selected vitamins and minerals, e.g. vitamin B12, iron, magnesium

Systematic use

Non-systematic use

Previously used

Never (not yet) ${ }^{b}$

Non-systematic use

Previously used

Never (not yet) ${ }^{\mathrm{c}}$

Systematic use

Creatine

\section{Caffeine pills}

Systematic use

$2 \%$

$4 \%$

$3 \%$

$90 \%$

$22 \%$

$14 \%$

$13 \%$

$51 \%$

$10 \%$

$5 \%$

$15 \%$

$70 \%$

$61 \%$

Experience with 'in sport' use of NSAIDs ${ }^{e}$

Have never (consciously) decided to refrain from or minimise the use of legal products ${ }^{f}$

How athletes say they would react if (when) some competitors start using a new legal performanceenhancing drug ${ }^{\mathrm{g}}$

Use the same product and find other ways to enhance performance

Use the same product

Seek to enhance performance, but not necessarily using the same product

Focus on myself and do as I normally do

Influence (or not) of coach's/sports organisation's opinion regarding use of specific legal performance enhancing drugs

The coach is against it ${ }^{\mathrm{n}}$

Team Denmark/ the federation is against it '

Doping proximity: Knows someone who uses or has previously used doping ${ }^{\mathrm{j}}$
$9 \%$

$7 \%$

$7 \%$

$29 \%$

$55 \%$

$78 \%(21 \%)$

$76 \%(23 \%)$

$77 \%(21 \%)$

$88 \%(12 \%)$

$71 \%(29 \%)$

$78 \%(21 \%)$

$79 \%(20 \%)$

$75 \%(24 \%)$

$85 \%(16 \%)$

$73 \%(27 \%)$ 
In their training environment

In their sport

From other sports

Friends and acquaintances outside sport

$\begin{array}{rrrrr}14 \%(5 \%) & 13 \%(5 \%) & 20 \%(9 \%) & 12 \%(2 \%) & 6 \%(6 \%) \\ 24 \%(12 \%) & 23 \%(10 \%) & 27 \%(15 \%) & 29 \%(11 \%) & 13 \%(15 \%) \\ 23(12 \%) & 23 \%(15 \%) & 30 \%(11 \%) & 16 \%(12 \%) & 23 \%(12 \%) \\ 25 \%(8 \%) & 23 \%(6 \%) & 29 \%(8 \%) & 16 \%(9 \%) & 25 \%(13 \%)\end{array}$

$14 \%(5 \%)$

$29 \%(8 \%)$

$16 \%(9 \%)$

$25 \%(13 \%)$

Assessment of athlete's own training environment: competition logic, norms, performance and power ${ }^{\mathrm{k}}$

The athletes with the best results/best performances have most influence

$85 \%$

It is important to show that one is willing to make sacrifices best results for the sport

The coach gives most attention to the athletes with the

A specific bodily appearance (e.g. trimmed, skinny, muscular) gives social recognition

\section{$63 \%$}

$94 \%$

$53 \%$
$91 \%$

$62 \%$

$94 \%$

$55 \%$
$82 \% \quad 76 \%$

$74 \%$

$61 \%$

The patterns of use of legal substances/methods was explicitly linked to a sporting purpose, i.e. patterns of the use of drugs in relation to optimising/enhancing performance and taking care of the body by using different substances/methods as a supplement to normal physical training. The table displays three out of the 27 performance optimising and enhancing strategies measured (see Overbye, 2013: 123).

b The athletes who had not (yet) used caffeine pills were asked if they were interested in trying caffeine pills in the future: Yes $=4 \% /$ Will maybe $=13 \% /$ No $=67 \% /$ No, because I do not think it has an effect in my sport $=17 \%$. Note: no gender difference were found among the $21 \%$ of endurance sports athletes who use caffeine pills, but younger endurance athletes (of both genders) are more likely to not (yet) use caffeine pills. Caffeine drinks were used systematically or non-systematically in: Team Sport $=18 \% /$ Speed and Power $=22 \% /$ Endurance $=28 \% /$ Motor Skill Sport $=21 \%$.

${ }^{\mathrm{c}}$ The athletes who had not (yet) used additional selected vitamins and minerals in their sport - with a sporting purpose were asked if they would like to do so in the future: Yes $=21 \% /$ Will maybe $=41 \% /$ No $=30 \% /$ No, because I do not think it has an effect in my sport $=8 \%$.

$d$ The athletes who had not (yet) used creatine were asked if they were interested in using it in the future: Yes $=9 \% /$ Will maybe $=22 \% / \mathrm{No}=56 \% / \mathrm{No}$, because I do not think it has an effect in my sport $=13 \%$.

e NSAIDs is short for Non Steroidal Anti-Inflammatory Drugs. The percentage covers the athletes who have used NSAID in their sport once or more.

${ }^{f}$ Reasons for not having (consciously) decided to refrain from using legal products $(n=274)$ were: $27 \%$ felt it was important to seek to enhance performance with all available legal means; $38 \%$ did not see why one should refrain from using legal means; $24 \%$ reported they always followed their coaches'/experts' recommendations and trusted that these were optimal; $52 \%$ had never come across a legal means that they felt the need to refrain from using or minimise the use of (Overbye, 2013: 138)

9 The answers to the four categories of possible reactions were formulated based on the different patterns of responses found in interviews with elite athletes (Overbye, 2013).

$\mathrm{h}$ The numbers not in parenthesis give the proportion of athletes who report to be less likely to want to use the drug if the coach is against it; the proportion of athletes who say the coach's opinion has "no influence" is displayed in parenthesis. $1 \%$ reported that if their coach was against the drug, it would "increase" their wish to use it.

${ }^{i}$ The numbers not in parenthesis give the proportion of athletes who report to be less likely to want to use the drug if Team Denmark or their federation is against it; the proportion of athletes who say that Team Denmark and their federation sports opinion have "no influence" is displayed in parenthesis. $0.7 \%$ reported that if Team Denmark or their federation was against the drug, it would "increase" their wish to use it.

${ }^{\mathrm{j}}$ The percentage gives the proportion of athletes who answered that they knew someone who doped or had doped. The numbers in parenthesis refer to the percentage of athletes who answered "maybe, but I am not absolutely sure". Note: these numbers are based purely on the answers from the participants $(71 \%, n=549)$ of the current study and another survey assessing how athletes perceive doping and anti-doping efforts (Overbye, 2013).

k The percentages give the proportion of athletes who answered that the statement "Corresponds completely" or "fairly well" to their training environment. 


Theme Athletes elaboration on side-effects

Naming the particular side-effect(s) the athletes feared

Naming the specific substance or method they feared

Reservations when answering the question

Other explanations and comments
Harm/damage to body and health (29); fear of negative impact on life, e.g. physical and mental health after sports career has ended (17); blood clots (13); hormone levels (7); damage to organs, e.g. liver, kidneys, heart (7); fear of side-effects in general or unknown side-effects (7); fear of dependency (6); early death (6); fear of heart problems/heart attack (5); mental illness (5) or mental side-effects in general (5); high blood pressure (3); heart seizure (3); virility (4), sexual side-effects, e.g. impotence (3); general fear of side-effects of medicine (3); cancer (2); impact on physical appearance (2); acne (2); mood swings (2); mental side-effects, e.g. depression (2), small testes (2); aggressiveness (1); side-effects associated with substances that increase muscle mass (1), illness (1), side-effects of one substance will lead to use of other substances that can be dangerous (1); arteriosclerosis and other symptoms which impact lifestyle (1); stiff heart muscles (1); thick blood (1); reduced quality of life (1); not safe, fear of needles (1); related to gender ? (1); mutating cells (1); tiredness (1); dizziness (1); weakening of the bone density (1).

Fear of anabolic steroids, e.g. testosterone (22); fear of EPO (13); fear of growth hormone (8), blood transfusion (4), cortisone (2), diet medicine (1)

Need to have control of the side-effects first (2), need to be sure it is safe (1); AAS have side-effects, but assumption is that they will be provided under medical supervision (1) faith in qualified medical supervision (1); I answered, 'I do not know' in the cases where I wasn't sure if the substance would damage my health; if it does, I certainly won't use it (1)

Not natural (2), Lack of insight, knowledge and agreement between doctors, and therefore, I do not dare trust them (1); I want to be responsible for my own performance (1); Is it worth it? (1); I do not want to do this to my body (1); I said no to steroids and cortisone, etc. because I do not believe the effect offsets the side-effects (1), I am aware of side-effects regarding all the listed substances (1); I do not consider side-effects but want to be as good as possible with the body I have got and not improve performance level by ingesting the best substances (1); No matter what side-effects they might have, I would feel like I went from practising a healthy sport to destroying myself (1); I do not want to experiment with my body (1); I would NEVER use medicines which CAN harm the body, illegal or not (1) Others (7).

Table A1: The numbers in parentheses indicate the number of athletes reporting on the particular issue. Answers from 154 athletes who elaborated on what side-effects they considered when answering the first question. 